\title{
Avaliação da Citotoxicidade de Materiais Obturadores de Canal Radicular em Cultura de LINFÓCITOS HUMANOS
}

Dissertação apresentada ao Programa de Pós-Graduação em Odontopediatria, área de Concentração em Odontopediatria da Faculdade de Odontologia de Ribeirão Preto da Universidade de São Paulo, como requisito parcial para obtenção de título de Mestre em Ciências.

Aluna: Nicole Gonçalves Lima

Orientador: Prof. Dr. Alberto Consolaro

Ribeirão Preto 


\section{AUTORIZAÇÃO PARA REPRODUÇÃo}

AUTORIZO A REPRODUÇÃO E DIVULGAÇÃO TOTAL OU PARCIAL DESTE TRABALHO, POR QUALQUER MEIO CONVENCIONAL OU ELETRÔNICO, PARA FINS DE ESTUDO E PESQUISA, DESDE QUE CITADA A FONTE.

\section{Ficha Catalográfica}

Lima, Nicole Gonçalves

Avaliação da Citotoxicidade de Materiais Obturadores de Canal Radicular em Cultura de Linfócitos Humanos. Ribeirão Preto, 2016.

95p. : il. ; $30 \mathrm{~cm}$

Dissertação de Mestrado apresentada à Faculdade de Odontologia de Ribeirão Preto/USP - Programa de Pós-graduação em Odontopediatria.

Orientador: Prof. Dr. Alberto Consolaro

1. Viabilidade celular. 2. Endodontia. 3. MTT formazan. 4. Citotoxicidade. 5. Material obturador de canal radicular. 
Lima, N. Avaliação da Citotoxicidade de Materiais Obturadores de Canal Radicular em Cultura de Linfócitos Humanos.

Dissertação apresentada ao Programa de PósGraduação em Odontopediatria, área de Concentração em Odontopediatria da Faculdade de Odontologia de Ribeirão Preto da Universidade de São Paulo, como requisito parcial para obtenção de título de Mestre em Ciências.

Data da defesa:

BANCA EXAMINADORA

Prof. Dr.

Instituição:

Julgamento: Assinatura:

Prof. Dr.

Instituição:

Julgamento: Assinatura:

Prof. Dr.

Instituição:

Julgamento: Assinatura: 



\section{DADOS CURRICULARES}

\section{NiCOLE GonÇALVES LimA}

Nascimento 27 de Outubro de 1987 - Manaus- AM

Filiação Pedro Américo Panilha Lima

Nanete Mesquita Gonçalves

2009-2014 Curso de Graduação

Faculdade de Odontologia - Universidade Federal do Amazonas

2011-2012 Iniciação Científica - projeto de pesquisa intitulado "Prevalência de Queilite Actínica em Pescadores em Manaus-AM" (Bolsa FAPEAM). Orientadora:

Juliana Vianna Pereira

2012-2013 Iniciação Científica - projeto de pesquisa intitulado "Avaliação das lesões bucais dos drogadictos em recuperação na fazenda da esperança (ManausAM)" (Bolsa CNPq) . Orientadora: Juliana Vianna Pereira

2014-2015 Curso de Aperfeiçoamento no Atendimento Odontológico a Pacientes Especiais

2014-2016 Curso de Pós-Graduação (Mestrado) em Odontologia Área de concentração: Odontopediatria Faculdade de Odontologia de Ribeirão Preto da Universidade de São Paulo 

Cada um de nós compõe a sua história Cada ser em si Carrega o dom de ser capaz E ser feliz (Almir Sater / Renato Teixeira) 

Dedicatória 



\section{DEDICO ESTE TRABALHO}

Dedico esta, bem como todas as minhas demais conquistas, aos meus pais e irmã, pelo amor e apoio constantes para que eu atingisse meus objetivos e concluísse mais uma etapa da minha vida. A distância que nos separa é grande, e a saudade é maior ainda, mas o amor que sinto por vocês me dá forças para continuar trilhando meu caminho. AMO VOCÊS! 

Agradecimentos Especiais 



\section{AGRADECIMENTO ESPECIAL}

Á Deus por renovar minhas forças, iluminar meus passos e me manter no caminho certo durante todos esses anos.

Aos meus pais, Pedro Lima e Nanete Gonçalves, pelo apoio incondicional em tudo e sempre acreditarem nos meus sonhos. Se hoje sou capaz de buscar meus próprios interesses, foi graças à educação recebida ao longo de minha vida e à profunda admiração que tenho por vocês! Amo vocês.

A minha irmã, Luana Gonçalves Lima pelo companheirismo que sempre esteve ao meu lado, compartilhou comigo uma infância maravilhosa, uma adolescência entre tapas e beijos. Amo você.

A todos os familiares e amigos, que mesmo longe, sempre me apoiaram e comemoram comigo minhas vitórias.

Ao Prof. Dr. Alberto Consolaro, pela orientação e suporte para que esse trabalho fosse realizado, contribuindo para meu crescimento científico e pessoal. Um exemplo de professor a ser seguido, sempre disposto a ensinar a aprender. Muito Obrigada.

Ao Prof. Dr. Fabricio Kitazono de Carvalho, pela ajuda na execução do projeto.

Ao Prof. Dr. Paulo Nelson Filho, por todas as orientações durante o período do mestrado. Muito obrigada pela dedicação, paciência, disponibilidade em me socorrer nas horas de desespero e todos os ensinamentos passados.

A Profa. Dra. Léa Assed Bezerra da Silva, pela oportunidade de desenvolver esse trabalho e por acreditar na minha capacidade, fornecendo todo apoio e suporte.

A Profa. Dra. Lusânia Maria Greggi Antunes por ter disponibilizado o laboratório para tornar possível execução do trabalho. 
A Profa. Dra. Juliana Vianna Pereira, profissional em que me espelho, a qual despertou em mim o interesse pela pesquisa científica durante meu período de graduação na Universidade Federal do Amazonas (UFAM), obrigada por todo carinho.

Ao doutorando Vinicius Venancio por tornar possível a execução dos experimentos e por todos os ensinamentos passados.

Aos integrantes da Banca Examinadora, pelo tempo que dedicaram à análise deste trabalho.

Ás minhas amigas, que mesmo geograficamente distante, sempre se fizeram presente no meu dia a dia tornando- os mais leves: Carla Loureiro, Girlainny Damascena, Larissa Peixoto, Naime Said (e Laura Melo), Renata Sant'Ana. Sinto muita saudade de todas vocês.

Luiz Fernando Gracindo, Raísa Castelo, Caroline Borges e Patrick Osborne pela amizade, paciência, conforto nas horas difíceis, por todos os momentos de descontração e alegria, sem vocês essa jornada teria sido muito mais difícil.

Á minha madrinha, Naziette Mesquita Gonçalves, pela preocupação constante e telefonemas quase diários.

As minhas colegas de turma de mestrado, Laura Bastos, Thais Xavier e Raquel Morelli por compartilharem momentos bons e ruins.

Aos meus colegas (calouros) de mestrado Alessandra Menino, Ana Paula Moreno, Ana Maria Guerra, Arthur Cunha, Guido Vasquez, Letícia Sgarbi, Mariana Shirozaki, Thaise Taira por todo apoio dessa turma que me adotou e principalmente agradeço a Mariana Trevizan por encarar esse grande desafio comigo e tornar meus dias mais divertidos, pelos conselhos de vida e acadêmicos, pelas horas em laboratório e tornar minha jornada melhor. 
Agradecimentos 

AGRADECIMENTOS

À Universidade de São Paulo, na pessoa do atual reitor, Prof. Dr. Marco Antonio Zago e do vice-reitor, Prof. Dr. Vahan Agopyan.

À Faculdade de Odontologia de Ribeirão Preto da Universidade de São Paulo, na pessoa da Diretora Profa. Dra. Léa Assed Bezerra da Silva e o Vice - Diretor Prof. Dr. Arthur Belem Novaes Júnior.

À Coordenação do Curso de Pós-Graduação em Odontopediatria da Faculdade de Odontologia de Ribeirão Preto da Universidade de São Paulo, na pessoa da coordenadora, Profa. Dra. Raquel Assed Bezerra Segato e da vice-coordenadora, Profa. Dra. Léa Assed Bezerra da Silva.

À Fundação e amparo a pesquisa do Estado do Amazonas (FAPEAM), pela bolsa concedida.

Aos demais professores do Departamento de Clinica Infantil Faculdade de Odontologia de Ribeirão Preto da Universidade de São Paulo: Prof. Dr. Paulo Nelson Filho, Profa. Dra. Aldevina Campos de Freitas, Profa. Dra. Alexandra Mussolino de Queiroz, Profa. Dra. Andiara de Rossi, Profa. Dra. Maria Cristina Borsatto, Profa. Dra Kranya Victoria Díaz Serrano, Prof. Dr. Fabricio Kitazono de Carvalho pela convivência e pelos ensinamentos.

Aos funcionários e Pós-graduandos do Laboratório de Nutrigenômica da faculdade de ciências farmacêuticas de ribeirão preto da universidade de são Paulo por me receberem tão bem e por toda ajuda concedida no período em que estive neste laboratório.

Aos funcionários do Departamento de Clinica Infantil: Carolina Paes Torres Mantovani, Micheli Cristina Leite Rovanholo, Matheus Morelli Zanela, Filomena Leli Placciti, pela disponibilidade todo carinho e atenção com os pós-graduandos.

Aos técnicos de laboratório, Nilza Leticia Magalhaes e Marco Antônio dos Santos pela ajuda. 

Sumário 



\section{SUMÁRIO}

\section{RESUMO}

ABSTRACT

1. INTRODUÇÃO........................................................................................

2. PROPOSIÇÃO.......................................................................................... 41

3. MATERIAL E MÉTODOS...........................................................................

3.1 Avaliação da citotoxicidade dos materiais obturadores de canais radiculares por meio do ensaio do MTT.

4. Resultados.

5. DISCUSSÃo.

6. CONCLUSÃo.

REFERÊNCIAS................................................................................................

VERSÃo RESUMIDA EM INGLÊS. 

Resumo 



\section{RESUMO}

Lima, NG. Avaliação da Citotoxicidade de Materiais Obturadores de Canal Radicular em Cultura de Linfócitos Humanos. Ribeirão Preto, 2016. 95p. [Dissertação de mestrado]. Faculdade de Odontologia de Ribeirão Preto, São Paulo.

Durante a fase de obturação dos canais radiculares, pode ocorrer o contato direto do material obturador com os tecidos periapicais, por tempo indeterminado, o que pode retardar, dificultar ou impedir a ocorrência do processo de reparo, por isso, para o êxito do tratamento endodôntico, a seleção de um material de obturação do canal radicular adequado é tão essencial como a técnica operatória. Esse contato pode ocorrer por extravasamento na forma de "puff" ou mesmo sem extravasamento, pois componentes derivados desses materiais podem entrar em contato direto com os tecidos, através de numerosas conexões, como, por exemplo, os túbulos dentinários, canais acessórios, canais laterais e o forame apical, causando irritação e possível desconforto pós-operatório. Outra forma pela qual os materiais obturadores de canais radiculares podem entrar em contato com os tecidos periapicais é através do processo realização de tratamento endodôntico em dentes decíduos, devido ao processo de rizólise ou tratamento endodôntico em dentes imaturos (ápice aberto). Por esses motivos, a biocompatibilidade dos materiais obturadores de canais radiculares é de extrema importância, diante disso objetivo deste trabalho foi avaliar a citotoxicidade, por meio do Ensaio do MTT, de seis materiais endodônticos usados em dentes decíduos e permanentes (AH Plus ${ }^{\mathrm{TM}}$, GuttaFlow 2, Endomethasone N, Vitapex $\Re$, Calen $($ espessada e MTA ProRoot) recém espatulados, em cultura primária de linfócitos do sangue periférico de humanos, por 24 horas. Os resultados foram submetidos a análise estatística pelo teste one-way ANOVA e pós-teste de Tukey, com nível de significância de $5 \%$. Observou-se que o Endomethasone $\mathrm{N}$ foi o mais citotóxico sobre linfócitos, O AH Plus, e a Calen ${ }^{\circledR}$ espessada foram citotóxicas a partir de $25 \mathrm{mg} / \mathrm{mL}$, enquanto o MTA ProRoot, GuttaFlow 2 e o Vitapex $\circledR$ foram os menos citotóxicos sobre linfócitos humanos, podendo-se concluir que o Vitapex ${ }^{\circledR}$ (usados em dentes decíduos) e o GuttaFlow 2 e MTA ProRoot (usados em dentes permanentes) foram os materiais obturadores menos citotóxicos sobre linfócitos humanos.

Palavras chave: Viabilidade celular, endodontia, MTT formazan, citotoxicidade, Material obturador de canal radicular. 

Abstract 



\section{ABSTRACT}

Lima, NG. Evaluation of root canal sealers materials cytotoxicity in human Iymphocyte culture. Ribeirão Preto, 2016. 95p. [Dissertation]. Faculdade de Odontologia de Ribeirão Preto, São Paulo.

During the filling phase of root canals, there may be direct contact of the filling material with the periapical tissues, for an (indefinite) unknown period, which may delay, hinder or prevent the occurrence of the repair process. The objective of this study is to evaluate the cytotoxicity by MTT assay of six endodontic materials used in primary and permanent teeth (AH Plus тм, GuttaFlow 2, Endomethasone N, Vitapex $\AA$, Calen $\AA$ thickened and MTA ProRoot) newly spatulate in primary cultures of peripheral human blood lymphocytes for 24 hours. The results were statistically analyzed by one-way ANOVA and Tukey's test at 5\% significance level. It was observed that the Endomethasone $\mathrm{N}$ was the most cytotoxic material for the lymphocytes, the AH Plus, and Calen $\AA$ thickened were cytotoxic from 25 $\mathrm{mg} / \mathrm{mL}$, while the MTA ProRoot, GuttaFlow 2 and Vitapex $\AA$ were less cytotoxic for human

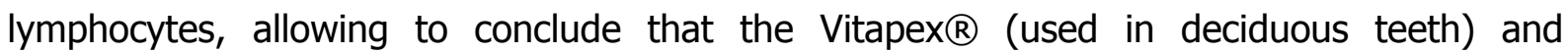
GuttaFlow 2 and MTA ProRoot (used in permanent teeth) were less cytotoxic sealers on human lymphocytes.

Keywords: Cell viability, endodontics, MTT formazan, cytotoxicity, root canal sealer 

1. Introdução 



\section{INTRODUÇÃO}

A obturação dos sistemas de canais radiculares tem por objetivo tornar hermético, da melhor maneira possível, o espaço modelado pelo preparo biomecânico. Os materiais obturadores de canais radiculares tem função de auxiliar no preenchimento das irregularidades e espaços existentes entre o material obturador principal e as paredes do canal, durante esse processo, os materiais endodônticos e seus produtos de degradação podem entrar em contato direto com as células dos tecidos periodontais, onde existem células-tronco do ligamento periodontal (PDLSCs) que estão presentes durante a reparação da periodontite apical. O material de preenchimento de raiz pode estimular PDLSCs a diferenciar-se em osteoblastos e cementoblastos, isolando assim o canal dos tecidos circundantes e promover o processo de reparo dos tecidos apicais danificadas, porém também podem influenciar negativamente no processo de reparo (Willershausen et al., 2013; Yoshino et al., 2013; Diomede et al., 2014; Camps et al., 2015; Garrido et al., 2015; Rodríguez-Lozano et al., 2015).

Para o êxito do tratamento endodôntico, a seleção de um material de obturação do canal radicular adequado é tão essencial como a técnica operatória. Cimentos endodônticos são geralmente irritantes para os tecidos periapicais, portanto, eles podem inibir os processos de cura e, consequentemente, influenciam o sucesso dos tratamentos de endodontia (Garrido et al., 2015). Os materiais obturadores de canal radicular presentes hoje no mercado especializado classificam-se de acordo com sua composição química: cimentos à base de óxido de zinco e eugenol, cimentos contendo hidróxido de cálcio, selantes à base de resina, cimentos à base de ionômero de vidro, à base de MTA, à base de biocerâmicas e aqueles a base de silicone (Yoshimine et al., 2003; Baraba et al., 2011) e independente do tipo, devem possuir determinadas propriedades físico-químicas como: fácil introdução no canal radicular, conseguir selar hermeticamente o canal radicular, resistente a contração, ser insolúvel aos fluidos bucais, bacteriostático ou impróprio para a proliferação microbiana, radiopaco, não podem afetar a coloração dentária, estéril, não ser irritante aos tecidos periapicais e ser de fácil remoção quando necessário (Lee 2002; Wu et al., 2006; Gatewood, 2007; Ozorio, 2012).

Alguns autores mostraram que quando o material obturador endodôntico é condensado, o mesmo pode extravasar para os tecidos periapicais, estimulando alterações celulares e respostas inflamatórias (Willershausen et al., 2011; Mendonça e Estrela 2001; Cotti et al., 2014; Ruparel, 2014). Consolaro e Bittencourt (2014), concordam que o extravasamento do material no periodonto apical, dificulta o desenvolvimento do processo 
de reparo e afirmam que as consequências de tais acidentes podem permanecer como lesões inflamatórias crônicas. Por isso é importante que os materiais obturadores de canais radiculares sejam bem tolerados pelos tecidos perirradiculares, visto que estes materiais podem ficar em contato direto com os tecidos periapicais por período indeterminado de tempo, seja quando extravasado na forma de ' 'puff' ' ou mesmo sem extravasamento, pois componentes derivados desses materiais podem entrar em contato direto com os tecidos, através de numerosas conexões, como, por exemplo, os túbulos dentinários, canais acessórios, canais laterais e o forame apical (Koch, 2001) causando irritação que resulta em reparação tardia e possível desconforto pós-operatório, daí sua biocompatibilidade ser de grande importância (Tepel et al ., 1994; Geurtsen \& Leyhausen 1997; Tanomaru Filho et al., 1998; Hauman \& Love 2003; Schafer \& Zandbiglari 2003; Seltzer, 2004; Huang et al., 2005; Donnelly et al., 2007; Spagnuolo et al.; 2008; Badole et al., 2013; Reichl et al., 2015; Rodríguez-Lozano et al., 2015).

A literatura fornece evidências de que esse extravasamento pode induzir uma reação inflamatória transitória ou grave, observadas clinicamente por dor a percussão ou pressão no dente tratado endodonticamente (Zmener 2005; Scarparo 2009; Van Landuyt et al.; 2012). Outros estudos mostram que a toxicidade de certos materiais pode variar de acordo com o período de tempo, ou seja, logo após sua manipulação ou seu endurecimento, mas de modo geral, a maioria apresenta citotoxicidade em algum momento. (Gerosa et al., 1995; Leonardo et al., 1999; Huang, Lii e Kao 2001) Existem vários testes capazes de testar a compatibilidade biológica desses cimentos endodônticos, em sua maioria são testes in vitro para determinar a resposta celular.

Além do extravasamento, que é comum na obturação do canal radicular dos dentes permanentes, existem outras condições nas quais os materiais obturadores entram em contato com tecido pulpar ou tecido periapical. Durante a realização de tratamento endodôntico em dentes decíduos, devido ao processo de rizólise dos dentes decíduos, o material usado anteriormente para tratar endodonticamente o elemento dentário fica em contato direto com os tecidos periapicais. Além disso, em tratamentos endodônticos de dentes permanentes imaturos, com rizogênese incompleta, há também contato direto de materiais com os tecidos do periápice (Queiroz et al., 2011). Um material de obturador ideal para dentes decíduos deve ser facilmente colocado e retirado, deve ter uma reabsorção semelhante à da raiz primária, não deve oferecer resistência a ponto de desviar ou modificar a erupção do dente permanente, deve ser radiopaco e não descolorir o dente, deve aderir às paredes, não deve contrair e deve possuir propriedades anti-sépticas, bem como ser inofensivo para os tecidos periapicais e germe de dente permanente (Rifkin 1980; Kubota et 
al. 1992; Fuks 2000; Fuks et al. 2002 ; Mortazavi \& Mesbahi 2004 ). Nenhum dos materiais disponíveis atualmente cumpre todos os critérios acima mencionados (Pramila et al., 2016).

Levando em consideração que a resposta imunológica é desencadeada por agentes de natureza proteica, os fabricantes de materiais obturadores de canal radicular preocupamse em não adicionar qualquer componente proteico em sua composição, com isso, quando materiais como cimentos obturadores, guta-percha, fios de sutura ou resinas, quando entram em contato com nossos tecidos, promovem inflamação inespecífica, pois não induzem respostas imunológicas ou imunogênicas (Consolaro e Bittencourt 2014).

A biocompatibilidade pode ser definida como a capacidade de um material exercer suas funções específicas, quando aplicado em tecidos vivos, sem causar danos ou prejuízos ao mesmo (Jorge, 2004; Anusavice, 2013). Quando um material não é biocompatível com os tecidos, o mesmo pode causar reações inflamatórias, alérgicas ou de fundo mutagênico/carcinogênico (Al-Hiyasat 2010).

Entre as várias metodologias recomendadas para avaliar a biocompatibilidade e citotoxicidade de materiais dentários em diferentes níveis de investigação, o uso de cultura de células in vitro faz parte dos protocolos mais utilizados por pesquisadores (Ratanasathien et al., 1995; Martins et al., 2013) devido à homogeneidade das amostras e à facilidade de uma padronização, pois é possível o controle de fatores tais como: $\mathrm{pH}$, temperatura, pressão osmótica, tensão de CO2 e de O2 (Freshney, 1990). Os primeiros estudos in vitro utilizando cultura celular para avaliar a citotoxicidade de materiais dentários foi realizado no final da década de 1960 (Kawahara et al., 1968; Grant 1995; Vidal, 2007). A cultura celular é derivada de células dispersas removidas a partir do tecido (Wataha, 2001). Culturas de células primárias são produzidas a partir de células retiradas de um tecido através de processos de desagregação por métodos mecânicos, enzimáticos ou químicos. As células primárias possuem morfologia idêntica ao do tecido das quais se originam. A cultura primária permite pouco número de divisões (ou passagens) celulares, após as quais entram em estado de senescência e morrem, ainda assim, muitos cientistas preferem utilizar culturas primárias em seus experimentos uma vez que estas células mantêm as características fisiológicas do tecido de origem, podendo ser consideradas, portanto, como representativas das condições naturais de um organismo (Schmalz, 1994; Martins et al., 2013). Estas células são obtidas pelo sangue, órgãos (rins, fígado, linfonodos, baço, timo, pâncreas) e organismos (embriões) (Takahashi et al. 1990).

De acordo com a Internacional Standart Organization (ISO) 10993-5, o ensaio de citotoxicidade in vitro é o primeiro teste para avaliar a biocompatibilidade de qualquer material para uso em dispositivos biomédicos; após comprovada sua propriedade citotóxica, 
os ensaios em animais devem ser realizados, e os testes em seres humanos são realizados apenas se o material apresentar comportamento adequado nos testes com animais.

Existem vários testes in vitro para avaliar a citotoxicidade de diversos materiais, um deles é o ensaio do MTT (3-(4,5-dimetiltiazol-2il)-2-5-difenil-2H tetrazolato de bromo), que avalia a viabilidade celular através a atividade mitocondrial. Este teste é bem aceito na literatura para avaliação de materiais endodônticos (Al-Hiyasat, Tayyar e Darmani 2010; Ashraf et al., 2012; Scelza, Coil e Alves 2012; Candeiro et al., 2015; Mestieri et al. 2015; Rodríguez-Lozano et al., 2015; Silva et al., 2015).

Silva et al, em 2016, estudaram em células V79 (fibroblastos de hamster chinês os efeitos citotóxicos de dois cimentos endodônticos experimentais a base de extratos naturais (Copaifera multijuga e Ricinus communis) associados ao hidróxido de cálcio e ao óxido de zinco. Compararam os cimentos novos a cimentos já usados na endodontia atual, AH Plus, EndoREZ, Real Seal SE) e observaram a citotoxicidade dos mesmos pelo ensaio do MTT e puderam concluir que o material a base de rícino apresentou uma ótima viabilidade celular, enquanto os demais apresentaram algum nível de citotoxicidade.

Mestieri et al. em 2015 avaliaram em células da polpa dentária humana a biocompatibilidade de materiais à base de silicato de cálcio, em 3 diferentes diluições, utilizando o ensaio do MTT e puderam concluir que o MTA Plus apresenta boa viabilidade celular nas 3 diluições testadas (1:2, 1:3, 1:4).

Konjhodzic-PrCIC et al., em 2015, estudaram a biocompatibilidade de cimentos endodônticos (GuttaFlow, AH Plus, Apexit e EndoREZ) em células L929 de fibroblastos de ratos por meio do ensaio do MTT. Os cimentos foram testados recém-misturados, após 24 horas, 48 horas e 7 dias. Os cimentos Apexit, Gutta Flow e AH Plus apresentaram baixa citotoxicidade em todos os períodos estudados, EndoREZ mostrou-se moderadamente citotóxico quando recém misturado e pós 7 dias e pôde concluir que este cimento não deve ser o de primeira escolha no uso clínico.

Martins et al., em 2013, avaliaram a citotoxicidade de cimentos obturadores em 12, 24 e 72 horas, utilizando células endoteliais ECV-304 (células do cordão umbilical humano) pelo ensaio do MTT. Entre os materiais estudados, concluíram que o Endofill foi o mais citotóxico e o Gutta Flow o menos citotóxico.

Ashraf et al, em 2012, avaliaram três cimentos a base de resina (AH Plus, EndoREZ e Epiphany) em células $L 929$ (fibroblasto de rato), os materiais foram colocados em contato com as células recém misturados e após a presa, foram também feitos extratos dos materiais e testados a citotoxicidade em 3 tempos diferentes (1 hora, 24 horas e 72 horas) 
utilizando o ensaio do MTT. Concluíram que os três materiais são citotóxicos, em todos os tempos estudados, assemelhando-se ao controle positivo (Pulp Canal Sealer).

Yilmaz et al., em 2012, avaliaram o efeito citotóxico de sete cimentos endodônticos presentes no mercado, Sealite Ultra, Tubli-Seal, Tubli-Seal EWT, Pulp Canal Sealer, Pulp Canal Sealer EWT, Endomethasone N, e Apexit Plus em células L929 usando o ensaio do MTT. Os cimentos foram diluídos em 1:32, 1:16, 1:8, 1:4 e 1:2. Em todas as diluições 0 Endomethasone $\mathrm{N}$ apresentou baixa viabilidade celular, enquanto o Apexit Plus, a base de hidróxido de cálcio, apresentou viabilidade celular ótima em todas as concentrações estudadas.

Existes na literatura trabalhos em várias áreas da saúde que usam linfócitos em ensaios in vitro (Aravind et al., 2016; Dhivya et al., 2016), porém não há relatos na literatura especifica, até o presente momento de trabalho que tenha avaliado a citotoxicidade de materiais obturadores de canais radiculares, por meio do ensaio do MTT usando linfócitos humanos periféricos. 

2. Proposição 



\section{PROPOSIÇÃo}

Levando em consideração que uma série de materiais endodônticos entra no mercado todos os dias, tais compostos podem potencialmente entrar em contato com os tecidos bucais por um longo período de tempo. Dados de citotoxicidade desses agentes são de extrema importância, pois muitos deles ainda não foram investigados neste contexto e existem muitas controvérsias na literatura. Assim, o objetivo deste estudo foi fornecer uma análise sobre o potencial citotóxico de 06 compostos utilizados atualmente na prática endodôntica por meio do ensaio do MTT com linfócitos do sangue periférico humano. 

3. Material e Métodos 



\section{MATERIAL e Métodos}

\subsection{Avaliação da citotoxicidade dos materiais obturadores de canais radiculares por meio do ensaio do MTT}

\section{Procedimentos Éticos}

Inicialmente, o presente projeto foi submetido à apreciação do Comitê de Ética em Pesquisa da Faculdade de Odontologia de Ribeirão Preto (FORP-USP) sendo iniciado apenas após sua aprovação pelo numero de CAAE 41659915.2.0000.5419. Para a realização dos experimentos foram obtidas amostras sanguíneas $(10 \mathrm{~mL})$ de 8 doadores voluntários adultos, com idade entre 18 e 35 anos, de ambos os gêneros, saudáveis, não-fumantes, que não foram expostos à radiação nos últimos três meses e que não fizeram uso de antibióticos ou outros medicamentos por um período de três semanas. O sangue foi colhido por punção venosa antecubital em vacutainers heparinizados (Becton Dickenson, Plymouth, Reino Unido). Todos os doadores estavam familiarizados com o estudo e assinaram as permissões de suas amostras de sangue para ser usado para fins científicos.

\section{Preparo das amostras}

Foram analisados cimentos endodônticos usados em dentes permanentes (Ah Plus $^{\mathrm{TM}}$, GuttaFlow 2, Endomethasone N e MTA ProRoot) e materiais obturadores utilizados em dentes decíduos (Vitapex $\Re$, Calen $\AA$ espessada com óxido de zinco) na proporção de 1:0,65 como preconizada por Segato et al. em 2016 (Tabela 1). A confecção dos extratos dos diferentes materiais foi realizada em recipiente estéril, utilizando técnicas assépticas de acordo com as normas da International Organization for Standardization de número 1099312 (ISO 2004), na concentração de $100 \mathrm{mg} / \mathrm{mL}$. Os materiais foram manipulados seguindo as indicações do fabricante, logo após a manipulação foram submersos em meio de cultura incompleto (RPMI 1640) e levados a incubadora a $37^{\circ} \mathrm{C}$ por $24 \mathrm{~h}$. Posteriormente filtrados em filtros estéreis de $0,22 \mu \mathrm{m}$ e mantidos em geladeira a $4^{\circ} \mathrm{C}$. 
Tabela 1: Composição de cada material estudado e fabricante

\begin{tabular}{|c|c|c|}
\hline Material & Componentes & Ingredientes \\
\hline \multirow[t]{2}{*}{$\begin{array}{c}\text { AH Plus } \\
\text { (Dentsply De Trey, Suíça) }\end{array}$} & Pasta A & $\begin{array}{l}\text { Resina epóxica Bisfenol-A } \\
\text { e Bisfenol-B Tungstato de } \\
\text { cálcio Óxido de zircónio } \\
\text { Sílica Óxido de ferro }\end{array}$ \\
\hline & Pasta B & $\begin{array}{c}\text { Amina 1- adamantano } \\
\text { N,N'-dibenzoil-5-oxanonane-diamina-1,9- } \\
\text { TCD-diamina } \\
\text { Tungstato de cálcio } \\
\text { Óxido de zircônio } \\
\text { Óleo de silicone } \\
\text { Aerosil } \\
\end{array}$ \\
\hline \multirow[t]{2}{*}{$\begin{array}{c}\text { Endomethansone N } \\
\text { (Septodont, Paris, França) }\end{array}$} & Pó & $\begin{array}{l}\text { Acetato de hidrocortisona } \\
\text { Iodeto de timol } \\
\text { Óxido de Zinco } \\
\text { Estearato de Magnésio } \\
\text { Excipiente radiopaco }\end{array}$ \\
\hline & Líquido & Eugenol \\
\hline $\begin{array}{c}\text { Guttaflow } 2 \\
\text { (Coltene Whaledent, GmbH + } \\
\text { Co KG, Langenau, Suíça) }\end{array}$ & Cápsula & $\begin{array}{c}\text { Dióxido de zircônio Polidimetilsiloxano } \\
\text { Óleo de Silicone } \\
\text { Mistura de óxido de zinco } \\
\text { guta-percha em pó } \\
\text { Micro-prata (conservante) } \\
\text { Catalisador de platina Pigmento } \\
\end{array}$ \\
\hline $\begin{array}{c}\text { Calen } \AA \\
\text { (S.S. White, Rio de Janeiro, } \\
\text { Brasil) }\end{array}$ & Pasta & $\begin{array}{c}\text { Hidróxido de cálcio } 49,77 \text { g\%; } \\
\text { Óxido de zinco } \\
\text { Colofônia } \\
\text { Polietileno glicol400. }\end{array}$ \\
\hline $\begin{array}{c}\text { Espessada com Óxido de Zinco } \\
\text { (S.S. White, Rio de Janeiro, } \\
\text { Brasil) }\end{array}$ & Pó & Óxido de zinco \\
\hline $\begin{array}{c}\text { Vitapex }{ }^{\circledR} \\
\text { (Neo Dental, Washington, EUA) }\end{array}$ & Seringa & $\begin{array}{l}\text { Iodofórmio } 40.4 \% \text {; } \\
\text { Hidróxido de cálcio } 30 \% \\
\text { Silicone } 22.4 \%\end{array}$ \\
\hline \multirow[t]{2}{*}{$\begin{array}{c}\text { MTA ProRoot } \\
\text { (Dentsply, Konstanz, Germany) }\end{array}$} & Pó & $\begin{array}{c}\text { Óxido de cálcio } 44,16 \% \\
\text { Dióxido de silício } 21,25 \% \\
\text { Óxido de bismuto } 16,13 \% \\
\text { Óxido de alumínio } 1.87 \% \\
\text { Óxido de magnésio } 1.36 \% \\
\text { Óxido de ferro } 0.39 \% \\
\text { Óxido sulfúrico } 0.55 \% \\
\text { Pentóxido de fósforo } 0.27 \% \\
\text { Dióxido de titânio } 0,09 \% \\
\text { Óxido de sódio } 0,03 \% \\
\text { Cloro } 0,39 \% \\
\text { Dióxido de carbono } 13,51 \%\end{array}$ \\
\hline & Líquido & Água \\
\hline
\end{tabular}

Os materiais endodônticos utilizados foram testados logo após sua manipulação, a fim de tentar reproduzir a maneira a qual este entra em contato com os tecidos, tendo em vista que os materiais obturadores são inseridos na boca não completamente polimerizados, e assim, é provável que, durante um período relativamente curto depois da aplicação do material clínico, respostas locais são provocadas por componentes que não reagiram ou que reagiram apenas parcialmente, por isso foram confeccionados os extratos com materiais ainda frescos. 
Os linfócitos isolados entraram em contato com várias diluições do extrato de cada cimento (1:2 - 50mg/mL; $1: 4-25 \mathrm{mg} / \mathrm{mL} ; 1: 8-12,5 \mathrm{mg} / \mathrm{mL} ; 1: 16-6,25 \mathrm{mg} / \mathrm{mL} ; 1: 32$ - 3 , $125 \mathrm{mg} / \mathrm{mL}$ ), com objetivo de identificar quais concentrações apresentariam menos viabilidade celular e consequentemente maior citotoxicidade, foram comparadas aos controles, a fim de saber em quais concentrações cada material apresentava citotoxicidade à célula, através do ensaio do MTT, o controle positivo (MMS) foi usado apenas para comprovar a efetividade do teste.

\section{Preparo das culturas celulares}

Os linfócitos foram isolados das amostras sanguíneas utilizando-se o gradiente de densidade Ficoll (Hystopaque 1077, Sigma Aldrich, St Louis, MO, USA), coletados em tubos plásticos tipo Falcon, lavados e ressuspendidos na concentração de $4 \times 10^{5}$ células $/ \mathrm{mL}$ em meio RMPI 1640 suplementado com 10\% de soro fetal bovino e mistura de antibióticos penicilina (dose $100 \mathrm{UmL}^{-1}$ ) e estreptomicina (dose $100 \mathrm{U} \mathrm{LL}^{-1}$ ). As células foram semeadas em placas de cultura de 96 poços e levadas à incubadora por 24 horas, a $37^{\circ} \mathrm{C}$ e $5 \%$ de $\mathrm{CO}_{2}$ em estufa de atmosfera úmida (Thermo Eletronic). O ensaio do MTT foi utilizado como metodologia de avaliação da citotoxicidade.

\section{Ensaio do MTT}

O ensaio do MTT é colorimétrico para quantificar células viáveis, descrito primeiramente por Mosmann (1983), com pequenas modificações, utiliza o reativo 3-(4,5dimetiltiazol-2il)-2-5-difenil-2H tetrazolato de bromo, referido comumente como reativo do MTT.

O método avalia a atividade metabólica das células quantificando a redução metabólica do MTT a cristais de formazan ${ }^{1}$ (Figura 1). Assim, quanto maior a porcentagem de viabilidade celular, maior a formação dos cristais de coloração violeta. Para isso, os linfócitos foram isolados $\left(1,0 \times 10^{6}\right)$ em placas de 96 poços, seguido por incubação durante $24 \mathrm{~h}$ a $37^{\circ} \mathrm{C}$ em incubadora umidificada contendo $5 \%$ de $\mathrm{CO}_{2}$. Após este período, as células foram tratadas com $100 \mu \mathrm{L}$ de meio de cultura suplementado com soro fetal bovino (controle negativo) ou $100 \mu \mathrm{L}$ de cada extrato em diferentes concentrações $(1: 2-50 \mathrm{mg} / \mathrm{mL}$; $1: 4-25 \mathrm{mg} / \mathrm{mL} ; 1: 8-12,5 \mathrm{mg} / \mathrm{mL} ; 1: 16-6,25 \mathrm{mg} / \mathrm{mL} ; 1: 32-3,125 \mathrm{mg} / \mathrm{mL}$ ) o controle positivo experimental recebeu $100 \mu \mathrm{l}$ de uma solução de metilmetanosulfonato (MMS), que é um agente alquilante e carcinógeno o qual causa quebra das cadeias duplas do DNA, e a

\footnotetext{
${ }^{1}$ Cristais de Formazan: Os sais de tetrazolium (MTT) são reduzidos através de uma reação enzimática que envolve a oxidação do NADH/NADPH catalisada pelo complexo succinato-tetrazoliumredutase presentes somente em células viáveis. Quando reduzidos os sais tetrazolium formam o sal formazan que é hidrofóbico e colorido (solubilizado pela adição de DMSO) podendo ser quantificado por esctrofotometria.
} 
placa foi novamente levada à incubadora, por $24 \mathrm{~h}$ a $37^{\circ} \mathrm{C}$. Após o tratamento, os poços receberam $20 \mu \mathrm{L}$ de MTT [brometo de 3- (4,5-dimetiltiazol-2-il) -2,5-difeniltetrazólio] (Sigma M2128, EUA) (500 $\mu \mathrm{g} / \mathrm{mL}$, concentração final) e as placas foram incubadas novamente durante $3 \mathrm{~h}$ a $37^{\circ} \mathrm{C}$ e $5 \%$ de $\mathrm{CO}_{2}$. Em seguida, as placas foram centrifugadas a 1500rpm durante 5 min e, invertidas para descartar o sobrenadante. O formazan formado é insolúvel e se precipita no poço, necessitando ser solubilizado antes da leitura, para isso $100 \mu \mathrm{L}$ de DMSO (dimetilsulfóxido) (Sigma D2650, EUA) foram adicionados em cada um dos poços. As placas foram mantidas sob agitação até à dissolução completa dos cristais ( 20 min) e, em seguida, a absorbância a $570 \mathrm{~nm}$ foi determinada num microreader Powerwave XS2 (Biotek).

A porcentagem de viabilidade celular foi calculada a partir da fórmula: \% de celular viáveis $=($ absorbância do tratamento $\times 100) /$ média do controle negativo.

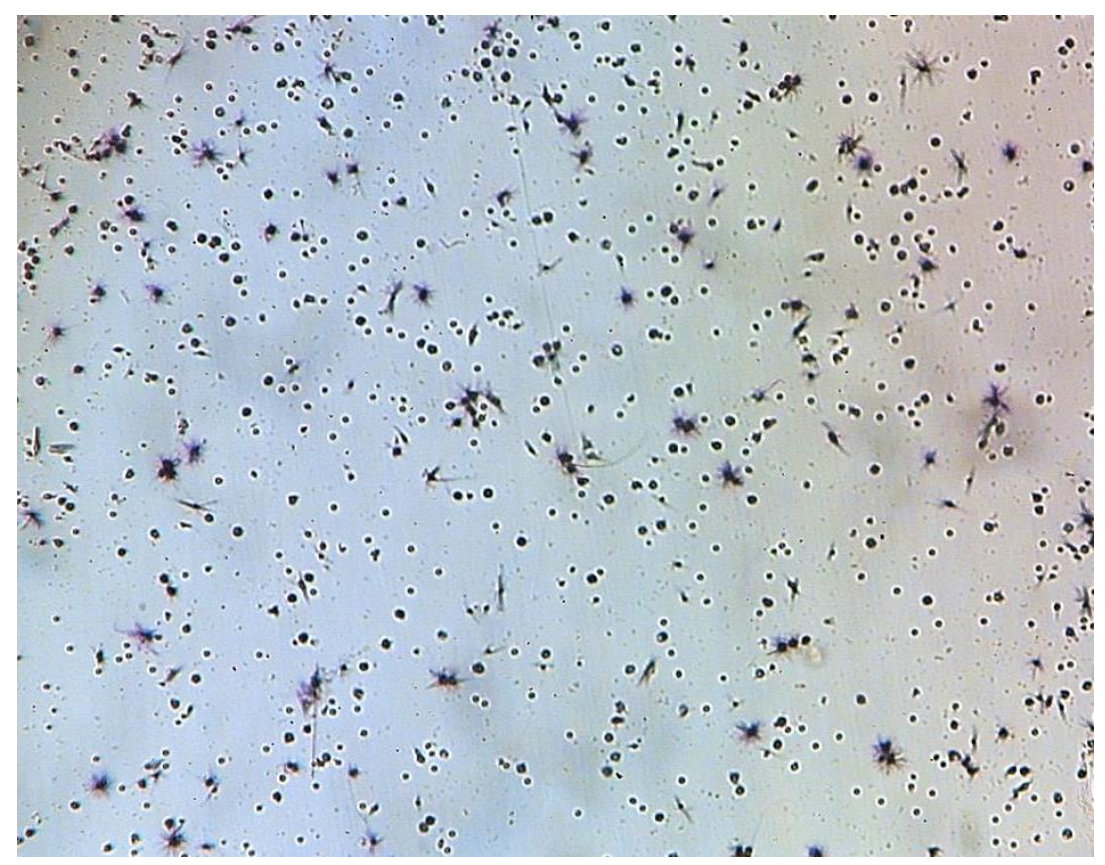

Figura1: Cristais de Formazan (microscopia eletrônica).

\section{Determinação da validade do ensaio}

A validade do ensaio foi determinada a partir das respostas das células ao tratamento pelos controles positivo (metil metano sulfonato-MMS) e negativo (meio de cultura RPMI-1640 suplementado com soro fetal bovino). O MMS é um agente alquilante com propriedades citotóxicas e genotóxicas. Esta substância apresenta uma resposta citotóxica dose-dependente bem definida na literatura, caracterizando-se como um bom controle positivo para os tratamentos (Wyatt; Pittman, 2006). A concentração de $100 \mu l$ de MMS foi selecionada para utilização como controle positivo. O controle celular foi realizado através da observação microscópica dos poços de cultura que receberam somente o meio de cobertura. 


\section{Análise estatística}

Cada ensaio foi feito em quintuplicata. Os resultados foram analisados pelo software Graph Pad Prism 5 utilizando o método one-way ANOVA, pós teste de Tukey. O nível de significância adotado foi de $5 \%$. Todos os tratamentos foram comparados com o controle negativo (RPMI 1640 completo).

\section{Limitações dos métodos}

Por ser um método de avaliação de reações celulares, nem sempre o grau de citotoxicidade revelado para um material determinará a mesma reação nos tecidos, devido à incapacidade de determinar a interação entre estes e o material. 

4. Resultados 



\section{RESULTADOS}

O teste de Komogorov-Smirnov foi usado para verificar a normalidade dos dados. $\mathrm{O}$ teste One-way ANOVA e Tukey foram usados para comparação entre as médias. As várias diluições de cada material foram comparadas ao controle negativo, a fim de avaliar qual das diluições apresentavam melhor viabilidade celular dos linfócitos (Figuras 2).

Com relação ao estudo dos materiais obturadores em diferentes concentrações (Figura 2), observou-se que o Endomethasone $\mathrm{N}$ foi citotóxico sobre linfócitos a partir da concentração de $6,25 \mathrm{mg} / \mathrm{mL}$ ( $p>0,05)$. O AH Plus, e a Calen $®$ espessada foram citotóxicas a partir de $25 \mathrm{mg} / \mathrm{mL}(p>0,05)$. O GuttaFlow 2, o MTA ProRoot e o Vitapex® não foram citotóxicos em nenhuma das concentrações avaliadas $(p<0,05)$.

Assim, a citotoxicidade do Endomethasone N, do AH Plus e da Calen $\AA$ espessada foi concentração dependente. 

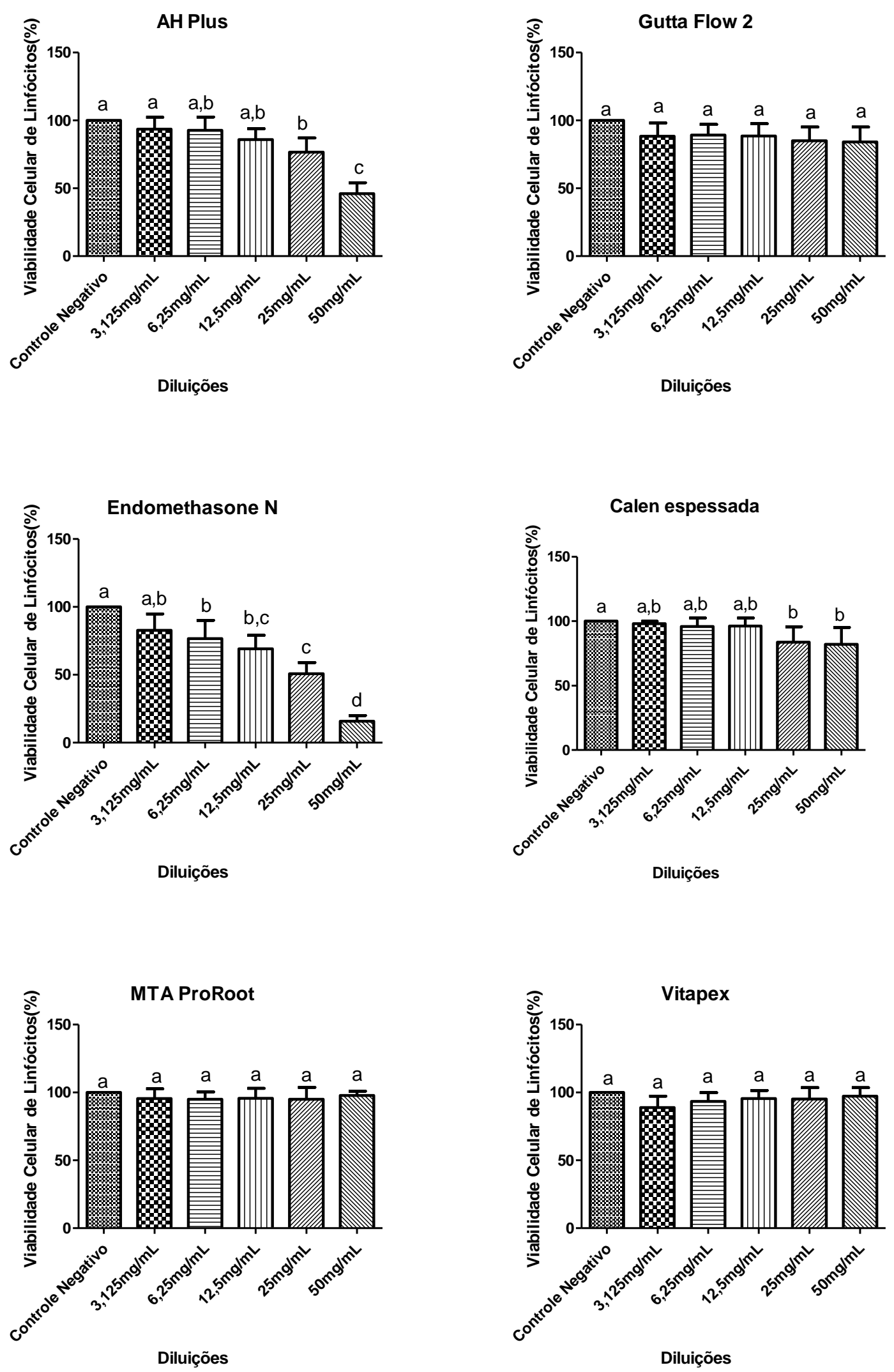

Figura 2. Viabilidade celular de linfócitos, após exposição aos materiais obturadores, nas concentrações de $50 \mathrm{mg} / \mathrm{mL}, 25 \mathrm{mg} / \mathrm{mL}, 12,5 \mathrm{mg} / \mathrm{mL}, 6,25 \mathrm{mg} / \mathrm{mL}, 3,125 \mathrm{mg} / \mathrm{mL}$ (dados expressos em médias e desvio-padrão). Cada experimento foi feito em quintuplicata. Análise ANOVA e pós teste de Tukey. Letras diferentes significam diferença estatisticamente significante $(p<0,05)$. 
Na análise comparativa entre os diferentes materiais obturadores, na diluição de $50 \mathrm{mg} / \mathrm{mL}$, observou-se que o Endomethasone $\mathrm{N}$ e $\mathrm{O} \mathrm{AH}$ Plus apresentaram os piores resultados com relação à viabilidade celular de linfócitos $(p<0,05)$, enquanto que 0 GuttaFlow 2, Calen $\AA$ espessada, MTA ProRoot e Vitapex $(\AA$ apresentaram maior viabilidade celular, sem diferença entre eles ( $p>0,05)$ (Figura 3 ).

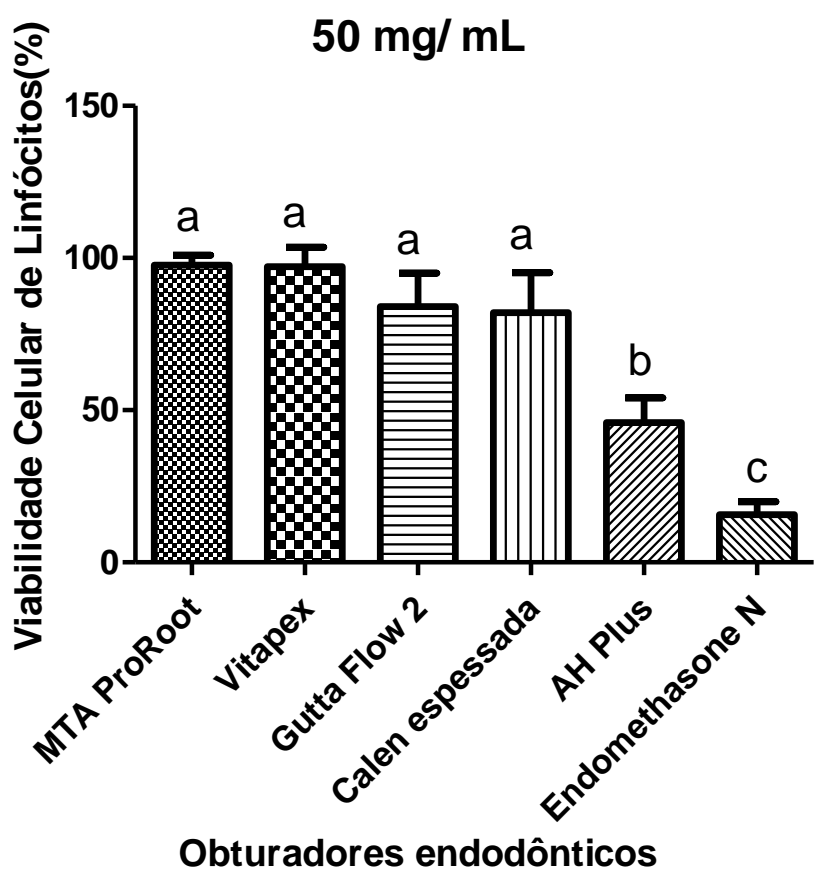

Figura 3. Comparação das médias de viabilidade celular de linfócitos, após exposição aos materiais obturadores, nas concentrações de $50 \mathrm{mg} / \mathrm{mL}$ (dados expressos em médias e desvio-padrão). Cada experimento foi feito em quintuplicata. Análise ANOVA e pós teste de Tukey. Letras diferentes significam diferença estatisticamente significante $(p<0,05)$. 

5. Discussão 



\section{DISCUSSÃo}

Existem diversas publicações que relatam a citotoxicidade in vitro de diversos cimentos endodônticos (Willershausen et al., 2013; Otti et al . 2014., Diomede et al., 2014). A maioria dos cimentos endodônticos convencionais demonstraram pouca biocompatibilidade tecidual e alta citotoxicidade em cultura de célula, principalmente quando se encontram recém misturado (Gandolfi \& Prati 2010, Chang et al., 2014). Estes materiais, ao entrarem em contato direto com os tecidos conjuntivos apicais, podem levar a um processo de inflamação aguda, o qual resulta na destruição do parênquima periapical e a inflamação pode ser mantida por agentes infecciosos, bactérias, remanescentes de microorganismos mortos e corpo estranho (Vidal, 2007). Todos os materiais particulados que induzem apenas resposta inflamatória, e não imunogênica, são conhecidos como corpo estranho, quando há formação de granuloma na região apical ocasionado por extravasamento de material obturador, este é chamado de granuloma periapical tipo corpo estranho e difere do granuloma periapical clássico pelo fato desse ser induzido pela microbiota com alta capacidade imunogênica (Consolaro e Bittencourt 2014).

Em estudos in vitro, a avaliação da viabilidade celular é parte fundamental, pois a necessidade de distinção entre células viáveis e não viáveis pode estar relacionada com o objetivo principal do trabalho, como também pode ser uma informação necessária para correlação com outros parâmetros avaliados, ou ainda uma informação necessária para a correta interpretação dos resultados (Stoddart, 2011). Na região apical a morte dos linfócitos é focal e restrita. No contexto geral do corpo não representa efeito significativo. Quanto ao efeito local, pode favorecer a anacorese, onde as bactérias circundantes, são atraídas para áreas previamente inflamadas, dando origem a um foco infeccioso secundário e resíduo de materiais obturadores de canal radicular, quando extravasado, são atrativos para ocorrência desse processo (Aboudharam et al., 2000; Dezan Junior 2001).

O teste de escolha para o presente estudo foi o ensaio do MTT, descrito por Mosmann em 1983. Essa escolha foi feita tendo em vista que, a maioria das substâncias liberadas pelos materiais estudados são hidrófilas e susceptíveis a liberar componentes iônicos, com isso podem interferir na atividade de enzimas intracelulares e influenciar na permeabilidade da membrana celular. O método é amplamente utilizado para avaliação da citotoxicidade de diferentes compostos in vitro, utilizando tanto de linhagens de células primárias, como células já imortalizadas (Ho et al., 2012), foi desenvolvido como uma alternativa não radioativa ao método de incorporação de timidina ao DNA (Mosmann, 1983). 
O reagente do MTT, 3-(4,5-dimetiltiazol-2il)-2-5-difenil-2H tetrazolato de bromo, é adicionado no meio de cultivo celular incubado, onde as células metabolicamente ativas convertem, através de redução, o reagente de MTT em formazan, de coloração arroxeada, que possui uma absorção próxima de $570 \mathrm{~nm}$, as células mortas rapidamente perdem a capacidade de converter o reagente do MTT . O formazan formado é insolúvel e se precipita no poço, sendo também depositado no meio e na superfície celular, necessitando ser solubilizado antes da leitura. A quantidade de sinal gerada é dependente de vários parâmetros como: concentração de MTT, período de incubação, número de células viáveis e seu estado metabólico (Berridge e Tan, 1993; Berridge, Herst e Tan, 2005). As vantagens deste método são a sua rapidez e precisão, além disso, ele não requer radioisótopos (átomos que liberam radiação).

Apesar de ter um valor limitado, a cultura de células é um instrumento de grande importância na avaliação do mecanismo de biocompatibilidade dos materiais dentários. Esses materiais possuem composições químicas complexas e diferentes componentes que são liberados para as áreas circundantes, portanto para se investigar a resposta biológica de tais materiais, seria necessário avaliar o efeito biológico de cada substância liberada separadamente e em combinação, e ainda, seus efeitos sinérgicos e antagônicos, para isso é necessário que seja realizado mais de um método laboratorial para avaliar esses vários aspectos (Leirskar e Helgeland 1981).

As células escolhidas para realização do teste de citotoxicidade, no presente estudo, foram linfócitos do sangue periférico humano, ou seja, cultura de células primárias, as quais são as mais indicadas para os testes de citotoxicidade de materiais endodônticos (Huang et al., 2002). Em 1987, Preston et al. escreveram um protocolo a fim de padronizar o cultivo dessas células para realização de experimentos in vitro. Entre as vantagens de usar linfócitos em laboratório estão: sua estabilidade de cariótipo, não possuem grandes variações de duração do ciclo celular, estão disponíveis em grandes quantidades em pequenas amostras do sangue periférico, estão disponíveis por todo o corpo e circulam em todos os tecidos (Evans e O'Riordan 1975; Preston et al., 1987), além de serem células comuns aos tecidos periodontais. A presença de um efeito citotóxico in vitro não garante que o material é tóxico quando aplicados in vivo. Por outro lado, a ausência de um efeito citotóxico assegura uma boa resposta clínica (Martins et al., 2013).

A Food and Drug Administration (FDA- 1992) emitiu um memorando onde os protocolos relacionados aos testes de citotoxicidade foram padronizados pela ISO. Este documento descreve uma série de requisitos a serem seguidos e respeitados durante a realização dos testes in vitro de citotoxicidade de biomateriais. Segundo as normas ISO 
10993-5 existem três categorias de testes: teste por extração, teste de contato direto e teste de contato indireto. No presente estudo, optou-se por realizar os experimentos por meio de extração, e os extratos foram preparados com os materiais obturadores de canais radiculares recém-manipulados, pois se levou em consideração estudos feito por Spangberg e Pascon (1988) onde enfatizaram a importância do preparo dos biomateriais a serem testados in vitro quanto a sua citotoxicidade e puderam concluir que este deve ser realizado exatamente como na utilização da clinica diária, a fim de que os resultados sejam confiáveis.

Foi definido período experimental de 24 horas a fim de observar a intensidade de eventos relacionados à inflamação aguda (24-48h). Isso porque, nas primeiras horas após a agressão, o processo inflamatório estabelece uma defesa inata não induzida, caracterizada pela atuação do sistema complemento, com formação de compostos vasoativos, reconhecimento e fagocitose por macrófagos residentes e liberação de mediadores químicos. Estes levam a alterações vasculares e a migração de células inflamatórias para o local da agressão, especialmente neutrófilos que além de apresentarem atividade fagocitária, podem intensificar a resposta inflamatória pela liberação de enzimas, mediadores químicos e radicais tóxicos (Pereira; Bogliolo 2009; Siqueira, 2001a; Siqueira 2001b; Montenegro; Facchio 2004; Consolaro 2015). Linfócitos e plasmócitos são as células mais prevalentes no infiltrado inflamatório e relacionam-se com as respostas imunes de base celular e de síntese de anticorpos (Pereira e Bogliolo, 2009).

A biocompatibilidade de diferentes cimentos endodônticos varia consideravelmente. $\mathrm{Na}$ tentativa de encontrar um vedante ideal, muitos materiais têm sido desenvolvidos com base nos cimentos de ionômero de vidro, óxido de zinco e eugenol, hidróxido de cálcio, resinas, biocerâmicas, agregado trióxido mineral (MTA) e silicone (Mandal et al., 2014). Diante da vasta gama de opções de materiais obturadores, apresentando diferentes prós e contras, a biocompatibilidade necessita ter prioridade, uma vez que alterações periapicais podem levar a alterações em todo o organismo, visto que as células do Sistema Fagocitário Mononuclear podem fagocitá-los e distribuí-los sistemicamente. Assim, o objetivo deste estudo in vitro foi avaliar os possíveis efeitos citotóxicos de seis diferentes materiais obturadores de canais radiculares, sobre linfócitos humanos. A realização do presente experimento comparou os materiais entre si e exibiu suas características em relação à citotoxicidade, correlacionando essa alteração a nível celular com a dor pós-operatória e o seu potencial de favorecer ou atrapalhar o processo de reparo periapical.

Dentre as propriedades inerentes a um bom cimento obturador, é importante ressaltar que sua solubilidade e desintegração devem ser as menores possíveis, para que o mesmo possa proporcionar um melhor selamento, favorecendo o sucesso clínico (Anusavice, 
2013). De acordo com Perassi (2009), os materiais obturadores do canal radicular devem preencher requisitos biológicos tais como: ter pouca solubilidade, não estimular resposta inflamatória ou estimular reposta que se desenvolva dentro dos parâmetros que permitam ao tecido o reparo e o isolamento do material obturador dos tecidos conjuntivos por meio de formação de capsula fibrosa após o período inicial de reparação e não promover persistência de infiltrado inflamatório intenso ou moderado que impeça ou retarde o inicio do reparo. A solubilidade é a capacidade que tem uma substância de se dissolver em outra, expressa pela concentração da solução saturada da primeira na segunda e a desintegração é o efeito de separa-se de um todo. De acordo com a norma 57 da ADA, um cimento obturador de canais radiculares não pode apresentar solubilidade e desintegração superiores a $3 \%$ e devem ter radiopacidade superior a $3 \mathrm{~mm}$ de alumínio.

Com a possibilidade de extravasamento dos cimentos através do forame, selantes podem ser solubilizados nos fluidos dos tecidos perirradiculares, fagocitados ou envolvidos por granuloma do tipo corpo estranho e tecido conjuntivo fibroso capsular. O destino do material dependerá suas propriedades físico-químicas, especialmente a solubilidade em água. Em relação a isso, um estudo realizado por Ricucci e colaboradores em 2016 demonstrou uma baixa solubilidade para o AH Plus, o que pode ser desejável quando se toma em consideração a estabilidade do material no espaço intra-radicular, mas, por outro lado, está pode não ser a melhor propriedade quando o material é extravasado para os tecidos perirradiculares.

Estudos realizados anteriormente como o de Cohen et al. 2000, Tai et al. 2002, Ozorio 2012 encontraram resultados semelhantes ao nosso, apontando o AH Plus como sendo um material citotóxico, essa citotoxicidade pode estar associada ao fato de ser um material a base de resina epóxi, liberando Bisfenol-A, um componente mutagênico e citotóxico presentes nestes materiais (Spångberg et al ., 1993; Cohen et al., 2000; Mandal et al., 2014).

Em nossos resultados, o AH Plus apresentou-se tóxico nas concentrações de 50 e $25 \mathrm{mg} / \mathrm{mL}$, evidenciando novamente o possível potencial danoso do bisfenol A presente nas resinas (Mandal et al., 2014). O formaldeído libertado, ainda que em pouca quantidade, pela reação de resina epóxi e amina para iniciar sua polimerização, o diglicidil e o éter também pode explicar a forte toxicidade inicial do AH Plus (Heil et al., 1996). Um estudo realizado por Leonardo et al. em 1999, comparou o AH Plus a outro cimento resinoso, o AH26, onde o $\mathrm{AH} 26$ mostrou-se mais citotóxico, com isso os autores puderam associar a citotoxicidade com a liberação de formaldeído, tendo em vista que o cimento AH26 liberou mais desta substância em comparação com o AH Plus. 
$\mathrm{O}$ AH Plus é uma modificação do cimento $\mathrm{AH}-26$, a principal diferença entre eles, segundo o fabricante, foi a retirada de formaldeído da formulação do $\mathrm{AH}-26$ o que deu origem ao AH Plus (Hargreaves e Cohen 2011), estudos experimentais em humanos e animais demonstraram que o formaldeído inalado provoca genotoxicidade, citotoxicidade e câncer (Costa 2011). Na odontologia, o primeiro relato da utilização do formaldeído para desinfecção dos canais radiculares, foi feito por Lepkowski, em 1897 (Ozorio 2012).

Está bem embasado na literatura os efeitos nocivos do formaldeído para os tecidos vivos (Spangberg et al., 1993; Huang 2005; Orstavik 2005). A natureza e o grau da reação tecidual vão depender da maneira que esse tecido entrou em contato com o material e a quantidade (Ho et al., 2007). Na literatura há relatos de parestesia do nervo mandibular atribuída à liberação de formaldeído e de ocorrência de reação alérgica (Koch et al., 2001).

Em 2005, a Agência Internacional de Pesquisa ao Câncer (IARC) mudou a classificação do formaldeído do grupo 2 (provavelmente cancerígeno em humanos) para o Grupo 1 (cancerígenos em humanos) (IARC 2006), devido surgimento de estudos associando essa substância ao risco câncer em vários órgãos (Pongsavee 2011; Goldstein 2011).

Na formulação do AH Plus o fabricante não inclui formaldeído, porém um estudo realizado por Ozorio em 2012 avaliou a quantidade de formaldeído liberado por alguns cimentos endodônticos, entre eles o AH Plus e teve como resultado que o mesmo liberou formaldeído tanto na espatulação quanto na extração do cimento. Em seu estudo ele observou que o cimento que mais liberou formaldeído foi o Sealer 26 durante o tempo de espatulação (7,40 mg.L - ${ }^{1}$ ) seguido do AH Plus que liberou 4,44 mg.L-1 durante seu tempo de presa. Estes valores estão muito acima do limite máximo de 0,1 ppm/15M recomendado pelo National Institute for Occupational Safety and Health (NIOSH) (INCA, 211), porém dentro do limite máximo permitido de exposição contínua que é de $5 \mathrm{ppm}$, sendo que, nos casos de pico, a concentração máxima deve ser de 10ppm segundo a Occupational Health and Safety Assessment Services OSHA (2011).

Quando comparado aos demais cimentos resinosos, o AH Plus libera pouca quantidade de formaldeído, diante disso, Cohen et al., em 2000, sugeriram que sua citotoxicidade se deve principalmente a resina epóxica presente na sua formulação. Essa informação foi confirmada por Huang et al. (2005), quando testaram as duas pastas do AH Pus separadamente e confirmaram maior citotoxicidade da pasta $A$, que contem resina epóxica. Huang (2005) evidenciou que além de serem citotóxicos, os cimentos a base de resina epóxica podem estimular a cicloxigenase-2 (COX-2), ativando o processo inflamatório. A cicloxigenase-2 (COX-2) é a enzima responsável pela síntese de prostaglandinas nos locais de inflamação (Huang et al., 2005). 
Com o objetivo de reduzir a reação inflamatória frente ao contato com material obturador e para que assim a diferenciação dos tecidos duros periapicais ocorra de forma mais rápida, alguns autores indicam a associação de um corticoide aos cimentos, tendo em vista que grande parte das reações inflamatórias que ocorrem após o tratamento endodôntico são agravadas pela natureza e característica biológica do material (Erausquin e Muruzabal, 1997). Com esta finalidade foi acrescido a hidrocortisona à formulação do Endomethasone N. Outra mudança que se deu na formulação do Endomethasone $\mathrm{N}$ foi a remoção do paraformaldeído, que estava presente na formulação do Endomethasone inicial (Gomes et al., 2004). Porém um estudo realizado por Ozorio em 2012 identificou liberação de formaldeído em três momentos de seu estudo, sendo a maior liberação durante sua espatulação, onde este libera 36,70mg.L-1.

Em um estudo realizado em 1999, Leonardo et al. investigaram e compararam a liberação de formaldeído entre o Endomethasone e o $\mathrm{AH}$ Plus, onde concluiu que o Endomethasone liberava maiores quantidades de formaldeído.

Savioli em 1998 analisou várias propriedades de alguns cimentos endodônticos, entre eles o Endomethasone $\mathrm{N}$ e pode observar que este cimento apresenta baixos valores de solubilidade, apresentando pouca perda de massa, sem que houvesse partículas em suspensão, como já foi dito anteriormente, a baixa solubilidade é uma característica favorável dos materiais obturadores, quando se deseja uma estabilidade intra-canal.

O Endomethasone $\mathrm{N}$, que é um cimento a base de óxido de zinco e Eugenol, no presente estudo mostrou citotoxicidade nas concentrações $50 ; 25 ; 12,5 ; 6,25 \mathrm{mg} / \mathrm{mL}$, apresentando-se o mais citotóxico entre os materiais estudos. Estes resultados foram apoiados por estudos realizados por Schwarze et al. em 2002 e Gerosa et al. em 1995, feitos em em fibroblastos 3T3 e células humanas do ligamento periodontal; e fibroblastos gengivais humanos, respectivamente, onde mostraram que o Endomethasone $\mathrm{N}$ inibiu fortemente a atividade mitocondrial durante as primeiras 24 horas. Esta constatação foi provavelmente devido à liberação de eugenol necessário para a manipulação do Endomethasone $\mathrm{N}$ (ISO 7405: 2008; Gulati et al., 1991; Schwarze et al., 2002) e também a hidrocortisona e o timol também presentes neste cimento que são reconhecidamente citotóxicos (Gerosa et al., 1995; Badole et al., 2013). Lindgvist \& Otteskog, em 1980, atribuíram a citotoxicidade dos cimentos endodônticos a base de óxido de zinco e eugenol, ao eugenol livre, liberado a partir manipulação do material. Isso pode explicar a alta citotoxicidade do Endomethasone $\mathrm{N}$, tendo em vista que o mesmo é manipulado com eugenol.

Huang et al., em 2002 realizaram um estudo com células primárias do ligamento periodontal e linhagem de células de hamsters V79, onde compararam a citotoxicidade de 
cinco cimentos obturadores de canais radiculares, entre eles estavam o Endomethasone $\mathrm{N} \mathrm{e}$ o AH Plus, e obtiveram como resultado que o Endomethasone $\mathrm{N}$ teve maior grau de citotoxicidade quando comparados aos outros cimentos, incluindo o $\mathrm{AH}$ Plus. Os resultados encontrados por esses autores são semelhante ao que encontramos em nosso estudo.

Um dos primeiros eventos da inflamação é o edema, Canova et al, em 2002 realizaram teste endemogenicos, injetando os cimentos recém-manipulados imediatamente no tecido conjuntivo subcutâneo do dorso de ratos, com o objetivo de quantificar o edema provocado nos tecidos quando em contato com os cimentos endodônticos, possibilitando com isso uma comparação da biocompatibilidade tecidual destes materiais e concluíram que o Endomethasone $\mathrm{N}$ apresentou uma reação inflamatória severa, a qual foi diminuindo com o tempo (6 horas).

Em 1984, Hume avaliou a liberação do eugenol dos cimentos a base de Óxido de Zinco e Eugenol em solução aquosa e afirmou que ocorre um declínio significativo desta liberação em função do tempo, e constatou que o eugenol apresenta uma liberação mais rápida e mais intensa em ambientes úmidos, atingindo níveis tóxicos com facilidade após uma hora e trinta minutos, permanecendo ativo por cerca de cem horas. Hume (1984) também observou que no tecido conjuntivo subcutâneo, a liberação de eugenol foi mil vezes maior que na dentina. Devemos levar em consideração que nosso estudo foi feito com extratos e os cimentos ficavam em contato direto com meio líquido por 24 horas, isso pode ter levado a uma maior liberação do eugenol. Schwarze et al., em 2002, observaram em seus estudos que o Endomethasone $\mathrm{N}$ pode desintegrar-se lentamente quando armazenado em meio úmido, com liberação de componentes citotóxicos em longo prazo. Ersev et al., em 1999 estudaram a citotoxicidade dos cimentos endodônticos, in vitro, e após 24 horas observaram que o Endomethasone $\mathrm{N}$ apresenta alto potencial citotóxico.

Silva, Santos e Zaia, em 2013, estudaram os efeitos citotóxicos de oito cimentos endodônticos (AH Plus, Epiphany, Endomethasone N, EndoREZ, MTA Fillapex, Pulp Canal Sealer EWT, RoekoSeal e Sealapex) a longo prazo. Observaram os efeitos dos cimentos por 5 semanas seguidas, as células 3T3 (fibroblastos) foram colocadas em contato com amostras dos cimentos recém manipulados e a citotoxicidade foi avaliada pelo ensaio do MTT. $O$ Endomethasone $\mathrm{N}$ apresentou viabilidade celular baixa até a segunda semana, após esse período, apresentou boa viabilidade celular.

Em um estudo realizado em 2003 por Bernath e Szabogo foi avaliado o grau de reação inflamatória provocado por quatro cimentos endodônticos, entre eles o Endomethasone $\mathrm{N}$, obturaram vinte e quatro canais radiculares de macacos sem extravasar material e oito canais com extravasamento de matérias, nos cortes microscópicos 06 meses 
após o tratamento, puderam observar que o grupo sem extravasamento, o Endomethasone apresentou reação inflamatória moderada, no grupo onde houve extravasamento, todos os cimentos apresentaram reação inflamatória, porém o Endomethasone iniciou um processo granulomatoso de corpo estranho.

Assim como ocorre nos cimentos resinosos, os cimentos a base de óxido de zinco e eugenol, mesmo que com baixa liberação de formaldeído, ativam a COX-2, resultando em uma inflamação periapical (Huang et al., 2005).

$\mathrm{O}$ Endomethasone $\mathrm{N}$ é um material com boa atividade antimicrobiana, devido à presença de eugenol e timol, porém esses componentes também aumentam a toxicidade do material, provocando danos aos tecidos periapicais, o que não compensa os benefícios das propriedades antibacterianas do material (Gomes et al., 2004).

GuttaFlow 2 é um sistema de enchimento a frio escoável a base de silicone-A, para canais radiculares, combinado com guta-percha, em forma de pó com um tamanho de partícula inferior a 30 um e um aferidor de produto. Os componentes são livres bolhas, misturados numa proporção de 4:1 na ponta de mistura do aplicador. O GuttaFlow 2 se diferencia do GuttaFlow por apresentar micropartículas de prata em sua composição, essa mudança se deu, pois, estudos provaram que as micropartículas de pratas não se apresentavam tão citotóxicas quanto à nanopartículas de prata. Isto pode ser explicado pela presença de um maior número de átomos na superfície de nanopartículas, causando uma maior reatividade em comparação com partículas maiores, tais como micropartículas, onde há menos átomos na superfície relacionada com o volume (Bouillaguet et al., 2006; Cha et al., 2008; Farré et al., 2009; Liu et al., 2011; Mandal et al., 2014), outro motivo pelo qual mudaram a fórmula foi para evitar a reinfecção do canal, segundo o fabricante as micropartículas fornecem esse tipo de proteção contra bactérias, aumentando assim sua atividade antibacteriana (Wainstein et al., 2016).

Mandal et al. em seu estudo de 2014, e Silva et al. em 2015 mostram que o GuttaFlow 2 possui excelente biocompatibilidade e baixo potencial citotóxico em fibroblastos gengivais, concordando com os resultados obtidos em nosso estudo, onde o mesmo apresentou boa viabilidade celular, sobre linfócitos, em todas as concentrações e quando comparado aos demais materiais obturadores na concentração de $50 \mathrm{mg} / \mathrm{mL}$, demonstrou resultado adequado, com alta viabilidade celular. Acardo et al., em 2014, e Silva et al. (2015) concluíram em seus estudos in vitro, que o GuttaFlow 2 não apresenta potencial citotóxico frente às células de ligamento periodontal de humanos (fibroblastos).

As evidências sugerem que o GuttaFlow 2 preenche as irregularidades do canal de maneira consistente e é biocompatível, porém seu tempo de endurecimento é inconsistente 
e pode ser retardado pela irrigação final com hipoclorito de sódio (Hargreaves e Cohen 2011).

Wainstein et al. (2016) avaliaram em seu estudo se a mudança na formulação do GuttaFlow 2 foi capaz de inibir $E$. Faecalis e revelaram que apesar da presença de micropartículas de prata, a qual deveria selar mais hermeticamente o forame apical, o GuttaFlow 2 não exerceu efeito contra a bactéria testada. Compararam também se o cimento resinoso o $\mathrm{AH}$ Plus exercida efeito contra a $E$. Faecalis e este apresentou resultado favorável na inibição bacteriana. O GuttaFlow, anteriormente apresentava resistência a essa bactéria por conter nanopartículas de prata, assim possuía mais íons de prata livre os quais ancoravam ou penetravam na parede celular bacteriana, modificando seu metabolismo (Nawal et al., 2011; Tran et al., 2013).

Assim como os materiais á base de silicone, os materiais á base de hidróxido de cálcio também são vistos como biocompatíveis com os tecidos periapicais, por esse motivo são amplamente usados em pulpotomia, apicificação e reparo de perfurações endodônticas, além de apresentarem efeito antimicrobiano (Correa et al., 2009; Desai e Chandler 2009). Desde sua introdução na odontologia em 1920 por BW Hermann, o hidróxido de cálcio $\left(\mathrm{Ca}(\mathrm{OH})_{2}\right)$ tem sido indicado para vários procedimento, alguns autores classificam os materiais á base de hidróxido de cálcio como “'selantes biológicos” (Beltes et al., 1995; Vajrabhaya e Sithisarn 1997; Geurtsen et al., 2001; Miletic et al.; 2000; Schwarze et al., 2002; Hawkins et al., 2015).

Com o tempo, o hidróxido de cálcio passou a ser substituído pelo Agregado Trióxido Mineral (MTA), principalmente para apicificação, essa mudança se deu, pois estudos revelaram que 0 dente submetidos a este tipo de tratamento usando $\left(\mathrm{Ca}(\mathrm{OH})_{2}\right)$ apresentavam um aumento na incidência de fratura radicular e enfraquecimento da dentina radicular (Stormer e Attramadal 1988; Cvek 1992; Andreasen et al., 2002; Hawkins et al., 2015) e existe estudo que aponta uma diminuição de $50 \%$ na resistência à fratura após 1 ano de exposição da raiz ao $\left(\mathrm{Ca}(\mathrm{OH})_{2}\right)$ (Andreasen et al., 2002).

Andreasen et al., em 2006, realizaram um estudo com dentes imaturos de ovelhas e testaram a resistência a fratura desses dentes após tratamento com hidróxido de cálcio e MTA ProRoot, foi usado solução alcalina como controle no tratamento. Os dentes foram divididos em quatro grupos, os grupos que receberam tratamento com solução salina, $\left(\mathrm{Ca}(\mathrm{OH})_{2}\right)$ e MTA foram armazenados por 100 dias, e um grupo recebeu tratamento com $\left(\mathrm{Ca}(\mathrm{OH})_{2}\right)$ e após 30 dias o $\left(\mathrm{Ca}(\mathrm{OH})_{2}\right)$ foi substituído por MTA e armazenado por 100 dias, esse estudo concluiu que o tratamento realizado com $\left(\mathrm{Ca}(\mathrm{OH})_{2}\right)$ e MTA não apresentou 
diminuição significativa na resistência da raiz, sendo esse o tratamento de escolha para dentes com necrose pulpar ou para realizar apicificação.

No presente estudo foi avaliado potencial citotóxico de dois materiais à base de hidróxido de cálcio, Calen $\AA$ espessada e Vitapex $\AA$, ambos apresentaram boa viabilidade celular, concordando com trabalhos anteriores quanto a sua biocompatibilidade (Marcantonio et al., 1984; Almushayt et al, 2006; Garlet et al., 2006; Correa et al., 2009; Desai e Chandler, 2009 ), apesar do Calen ${ }^{\circledR}$ espessada apresentar-se diferente do controle nas concentrações de $25 \mathrm{mg} / \mathrm{mL}$ e $50 \mathrm{mg} / \mathrm{mL}$, este continua apresentando boa viabilidade celular, e essa variação do controle pode ser atribuído aos demais componentes presentes na sua formulação (Silva et al., 2009). Quando comparados aos demais cimentos, na concentração de $50 \mathrm{mg} / \mathrm{mL}$, o Vitapex $\AA$ e 0 Calen $\AA$ espessada apresentam-se estatisticamente semelhantes, podendo classificá-los como não citotóxicos.

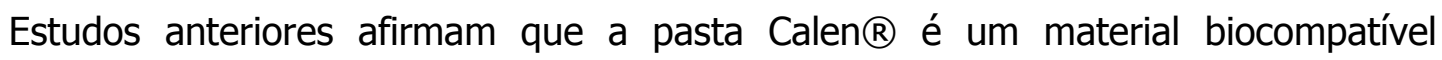
(Nelson-Filho et al., 1999; Leonardo et al., 2006), sendo utilizada como material obturador em dentes decíduos. Embora a pasta Calen ${ }^{\circledR}$ espessada com Óxido de Zinco apresente um elevado potencial antimicrobiano (Queiroz et al., 2009), a sua biocompatibilidade com os tecidos vivos ainda é pouco avaliada em estudos anteriores, o que torna difícil a discussão direta do presente resultado. Na literatura especifica apenas um estudo realizado por Pires et al., em 2015 avaliaram a citotoxicidade, estresse oxidativo e genotoxicidade in vitro de quatro pastas de iodofórmio e três pastas de hidróxido de cálcio, usaram células mononucleares do sangue periférico e DNA de timo de bezerro puro. Entre os materiais testados estavam a Calen $®$ espessada, e pôde concluir que os materiais a base de hidróxido de cálcio apresentaram aumento significativo na viabilidade celular, podendo ser considerado adequado para uso clinico. Resultado obtido no estudo anteriormente citado concorda com resultados obtidos no presente estudo. No entanto, é difícil comparar os resultados das diferentes experiências de cultura de células, devido as diferenças metodológicas, tais como o tipo de células, as formas de contato e os períodos de tempo experimentais (Sarigol et al., 2010).

Um estudo realizado por Queiroz et al., em 2011, observou a resposta do tecido conjuntivo subcutâneo de camundongo $B A L B / c$ frente a materiais obturadores de canais radiculares de dentes decíduos e concluíram que a incorporação do oxido de zinco na manipulação do Calen $®$ espessada, não afetou suas propriedades biológicas.

Um estudo realizado em 2010, por Tang et al., comparou o efeito antimicrobiano de três materiais usados como medicação intracanal em caso de periodontite apical crônica com fístula. Os materiais testados foram Vitapex $®$, hidróxido de cálcio e Iodopovidona. O estudo 
foi realizado com 90 pacientes os quais foram divididos aleatoriamente em três grupos onde cada grupo recebeu uma tipo de tratamento, junto a análise de desinfeç̧ão também foram avaliadas a escala de dor pós operatória dos paciente e puderam concluir que o grau de desinfecção foi semelhante nos 3 grupos, porém o grupo tratado com Vitapex $®$ obteve melhor controle da dor pós operatória quando comparados aos demais grupos.

Quando comparados a cimentos resinosos, os cimentos a base de hidróxido de cálcio apresentam uma resposta mais favorável dos tecidos perirradiculares (Huang et al. 2002).

Existe estudo o qual mostra que 0 Vitapex $\AA$ tem 0 efeito positivo frente a reparação óssea periapical in vitro, após tratamento endodôntico de periodontite apical crônica, auxiliando na maturação de tecido de granulação e este efeito pode ser relacionado com o aumento do nível local de expressão de proteínas morfogenéticas ósseas (BMP), sendo a BMP-2 conhecida por suas qualidades osteoindutoras (Xia et al., 2013).

O Vitapex $®$ é constituído principalmente por hidróxido de cálcio e iodofórmio. $O$ hidróxido de cálcio é fortemente alcalino e tem função antibacteriana no interior do canal radicular. Além disso, ele pode induzir a formação de tecido mineralizado, promover o reparo de cemento e estimular a calcificação dos tecidos periapicais. Seu pH alcalino também pode neutralizar os produtos ácidos de células inflamatórias e aumentar a atividade de fosfatase alcalina, por sua vez, o Iodofórmio libera iodo livre quando encontro tecido entra em contato com o tecido periodontal, auxiliando pra uma desinfecção a longo prazo e também pode eliminar a infecção do canal radicular e tecidos periapicais (Liang et al., 2000; Xia et al., 2013).

O MTA foi desenvolvido por Parirokh Torabinejad com o objetivo sanar a deficiência de materiais os quais poderiam ser usados para cirurgia parendodôntica, posteriormente foi usado para capeamento pulpar, pulpotomia, apicificação, reparo de perfurações radiculares e como preenchimento de canais radiculares, existem estudos que reconhecem o MTA como material bioativo, ou seja, capaz de induzir a formação de tecido mineralizado (Parirokh e Torabinejad 2010; Ceci et al., 2015). Esse material apresenta desvantagens como presa inicial lenta, dificuldade de manuseio e custo elevado (Kogan et al., 2006; Ber et al., 2007; Jafarnia et al., 2009).

As principais moléculas presentes no MTA são os íons cálcio e fósforo, que também são os principais componentes dos tecidos dentários, conferindo ao MTA uma excelente biocompatibilidade quando em contato com células e tecidos (Torabinejad et al., 1995), esses resultados concordam com o nosso trabalho, onde observamos que mesmo na concentração de $50 \mathrm{mg} / \mathrm{mL}$ o MTA ProRoot não apresentou potencial nocivo sobre as células 
quando comparado aos demais materiais, se assemelhando ao controle negativo, assim como apresentou viabilidade celular satisfatória em todas as concentrações testadas. Resultados que concordam com outros testes para verificar a biocompatibilidade, Osorio et al., em 1998 avaliaram a citotoxicidade do MTA para retro-obturações e concluíram que este foi o material que apresentou menor nível de toxicidade. Keiser et al., no ano de 2000 estudaram a citotoxicidade do MTA em culturas de células do ligamento periodontal humano, observaram que ele era biocompatível.

Quando o MTA em pó entra em contato com a água, forma hidróxido de cálcio e silicato de cálcio hidratado e transforma-se em um gel solidificado. Ocorre precipitação de hidróxido de cálcio, conferindo ao material alto pH (Camilleri 2008; Parirokh e Torabinejad 2010). Esse gel solidificado apresenta superfície granulada o que facilita a adesão, fixação e proliferação celular (Chen et al., 2016).

Quando comparado a outros materiais usados em proteção pulpar direta ou pulpotomia, como o hidróxido de cálcio e outros materiais de silicato de cálcio como o Biodentine (Septodont, Saint-Maur de Fossés, França), o MTA mostra maior frequência na formação de tecido mineralizado e uma ponte de dentina mais espessa e menos porosa, assim como menos inflamação pulpar (Parirokh e Torabinejad 2010; Kulan et al., 2016). Em ensaio de citotoxicidade através do MTT, com células odontoblásticas, Poggio et al. (2015) observou que o MTA e o Biodentine apresentavam viabilidade celular semelhante, enquanto os materiais à base de hidróxido de cálcio apresentavam baixa viabilidade celular.

Souza et al, em 2015 analisaram a radiopacidade o pH e a citotoxicidade do MTA ProRoot em comparação a um novo MTA (RetroMTA), utilizando células do ligamento periodontal de humanos e concluiu que quando comparados em radiopacidade, o MTA ProRoot é significativamente mais radiopaco, seguindo as recomendações da norma 57 da ADA, com liberação superior a 3mm de Al . O pH de ambos ficou entre 9,93 e 8, ou seja, ambos são alcalinos e o pH destes tende a diminuir ao longo do tempo e, para o teste XTT de viabilidade celular, ambos os materiais apresentaram resultados semelhantes, mostrando boa viabilidade celular em 24 e 48 horas.

A citotoxicidade está relacionada com o estresse, lesões reversíveis e irreversíveis das células que antecedem à necrose nas quais há grande liberação de mediadores e proteínas livres (Consolaro, 2015). Materiais com potencial citotóxico podem estar associados com a dor pós-operatória em endodontias. Após agressão celular, ocorre liberação e ativação de mediadores químicos da resposta inflamatória, como a histamina, bradicinina e prostaglandinas, sendo esta última associada ao processo de hiperalgesia, ou seja, a sensibilização das fibras nervosas sensitivas, responsável pela dor (Seymour e Walton 
1984). Para o bem-estar dos pacientes é fundamental a utilização de materiais que apresentem biocompatibilidade e preferencialmente ausência de citotoxicidade. Ademais, os testes realizados não permitem inferir a respeito de mutagenicidade e carcinogenicidade, mas estas propriedades devem ser avaliadas em outros estudos quanto ao seu potencial nas pastas e cimentos endodônticos e a citotoxidade representa os primeiros passos nesta direção. 

6. Conclusão 



\section{CONCLUSÃo}

Considerando as condições específicas deste trabalho, com base na metodologia empregada e nos resultados obtidos, pode-se concluir que:

$\checkmark$ Endomethasone $\mathrm{N}$ demostrou características de citotoxicidade sobre linfócitos nas diferentes concentrações, sendo o mais citotóxico entre os materiais estudados.

$\checkmark$ MTA ProRoot, GuttaFlow 2 e o Vitapex® apresentaram alta viabilidade celular e foram semelhantes ao controle negativo em todas as concentrações estudadas.

Na prática clínica o material de escolha deve ser sempre o mais biocompatível possível e preferencialmente não citotóxico mutagênico ou carcinogênico e para reunir todas essas informações são necessários mais estudos científicos, pois o material obturador ideal ainda não foi obtido considerando-se todas as naturezas das reações que induzem quando em contato com os tecidos vivos. 

Referências 



\section{REFERÊNCIAS}

1. Aboudharam G, Lascola B, Raoult D, Drancourt M. Detection of Coxiella burnetii DNA in dental pulp during experimental bacteremia. Microb Pathog. 2000 Apr;28(4):249-54.

2. Accardo C, Himel VT, Lallier TE. A novel GuttaFlow sealer supports cell survival and attachment. J Endod. 2014 Feb;40(2):231-4.

3. Al-Hezaimi K, Al-Hamdan K, Naghshbandi J, Oglesby S, Simon JH, Rotstein I. Effect of white-colored mineral trioxide aggregate in different concentrations on Candida albicans in vitro. J Endod. 2005 Sep;31(9):684-6.

4. Al-Hiyasat AS, Tayyar M, Darmani H. Cytotoxicity evaluation of various resin based root canal sealers. Int Endod J. 2010 Feb;43(2):148-53.

5. Almushayt $A$, Narayanan $K$, Zaki $A E$, George $A$. Dentin matrix protein 1 induces cytodifferentiation of dental pulp stem cells into odontoblasts. Gene Ther 2006;13:611620.

6. Andreasen JO, Farik B, Munksgaard EC. Long-term calcium hydroxide as a root canal dressing may increase risk of root fracture. Dent Traumatol. 2002 Jun;18(3):134-7.

7. Andreasen JO, Munksgaard EC, Bakland LK. Comparison of fracture resistance in root canals of immature sheep teeth after filling with calcium hydroxide or MTA. Dent Traumato/ 2006;22:154-6.

8. Aravind SR, Krishnan LK. Curcumin-albumin conjugates as an effective anti-cancer agent with immunomodulatory properties. Int Immunopharmacol. 2016 May;34:78-85.

9. Ashraf H, Moradimajd N, Mozayeni MA, Dianat O, Mahjour F, Yadegari Z.Cytotoxicity evaluation of three resin-based sealers on an L929 cell line. Dent Res J (Isfahan). 2012 Sep;9(5):549-53.

10. Badole GP, Warhadpande MM, Meshram GK, Bahadure RN, Tawani SG, Tawani G,Badole SG. A comparative evaluation of cytotoxicity of root canal sealers: an in vitro study. Restor Dent Endod. 2013 Nov;38(4):204-9.

11. Baraba A, Zelježić D, Kopjar N, Mladinić M, Anić I, Miletić I. Evaluation of cytotoxic and genotoxic effects of two resin-based root-canal sealers and their components on human leucocytes in vitro. Int Endod J.2011;44:652-61.

12. Beltes $P$, Koulaouzidou $E$, Kotoula $V$, Kortsaris $A H$. In vitro evaluation of the cytotoxicity of calcium hydroxide-based root canal sealers. Endod Dent Traumatol.1995 Oct; 11(5):245-9.

13. Ber BS, Hatton JF, Stewart GP. Chemical modification of proroot mta to improve handling characteristics and decrease setting time. J Endod. 2007 Oct;33(10):1231-4.

14. Bernáth M, Szabó J. Tissue reaction initiated by different sealers. Int Endod J. 2003 Apr;36(4):256-61. 
15. Berridge MV, Herst PM, Tan AS. Tetrazolium dyes as tools in cell biology: new insights into their cellular reduction. Biotechnol Annu Rev. 2005;11:127-52.

16. Berridge MV, Tan AS. Characterization of the cellular reduction of 3-(4,5dimethylthiazol-2-yl)-2,5-diphenyltetrazolium bromide (MTT): subcellular localization, substrate dependence, and involvement of mitochondrial electron transport in MTT reduction. Arch Biochem Biophys. 1993 Jun;303(2):474-82.

17. Bouillaguet S, Wataha JC, Tay FR, Brackett MG, Lockwood PE. Initial in vitro biological response to contemporary endodontic sealers. J Endod. 2006 Oct;32(10):989-92.

18. Brasil. Ministério da Saúde. Instituto Nacional de Câncer. Estimativa 2011: Incidência de Câncer no Brasil / Instituto Nacional de Câncer José Alencar Gomes da Silva, Coordenação de Prevenção e Vigilância. Rio de Janeiro: INCA, 2011.

19. Brzovic V, Miletic I, Zeljezic D, Mladinic M, Kasuba V, Ramic S, Anic I. In vitro genotoxicity of root canal sealers. Int Endod J. 2009 Mar;42(3):253-63.

20. Camilleri J. Characterization of hydration products of mineral trioxide aggregate. Int Endod J. 2008 May;41(5):408-17.

21. Camps J, Jeanneau C, Laurent P, About I. Bioactivity of a calcium silicate-based endodontic cement (BioRoot RCS): interactions with human periodontal ligament cells in vitro. Journal of Endodontics 2015. 41:1469-73.

22. Candeiro GT, Moura-Netto C, D'Almeida-Couto RS, Azambuja-Júnior N, Marques MM, Cai S, Gavini G. Cytotoxicity, genotoxicity and antibacterial effectiveness of a bioceramic endodontic sealer. Int Endod J. 2015 Aug 17.

23. Ceci M, Beltrami R, Chiesa M, Colombo M, Poggio C. Biological and chemical-physical properties of root-end filling materials: A comparative study. J Conserv Dent. 2015 Mar-Apr;18(2):94-9.

24. Cha K, Hong HW, Choi YG, Lee MJ, Park JH, Chae HK, Ryu G, Myung H. Comparison of acute responses of mice livers to short-term exposure to nano-sized or micro-sized silver particles. Biotechnol Lett. 2008 Nov;30(11):1893-9.

25. Chang SW, Lee SY, Kang SK, Kum KY, Kim EC. In vitro biocompatibility, inflammatory response, and osteogenic potential of 4 root canal sealers:Sealapex, Sankin apatite root sealer, MTA Fillapex, and iRoot SP root canal sealer. J Endod. 2014 Oct; 40(10):1642-8.

26. Chen I, Salhab I, Setzer FC, Kim S, Nah HD. A New Calcium Silicate-based Bioceramic Material Promotes Human Osteo- and Odontogenic Stem Cell Proliferation and Survival via the Extracellular Signal-regulated Kinase Signaling Pathway. J Endod. 2016 Mar; 42(3):480-6.

27. Cohen BI, Pagnillo MK, Musikant BL, Deutsch AS. An in vitro study of the cytotoxicity of two root canal sealers. J Endod. 2000 Apr;26(4):228-9

28. Consolaro A, Bittencourt G. Leakage of filling material: is it good or bad?. Dental Press Endod. 2014. May-Aug; 4(2):18-25. 
29. Consolaro, Alberto. Inflamação e Reparo: um sílabo para compreensão clínica e implicações terapêuticas. Dental Press editor. Maringá, 2009. 352 páginas.

30. Correa GT, Veranio GA, Silva LE, Hirata Junior R, Coil JM, Scelza MF. Cytotoxicity evaluation of two root canal sealers and a commercial calcium hydroxide paste on THP1 cell line by Trypan Blue assay. J Appl Oral Sci. 2009 Sep-Oct;17(5):457-61.

31. Costa S, Pina C, Coelho P, Costa C, Silva S, Porto B, Laffon B, Teixeira JP. Occupational exposure to formaldehyde: genotoxic risk evaluation by comet assay and micronucleus test using human peripheral lymphocytes. J Toxicol Environ Health A. 2011;74(1516):1040-51.

32. Cotti E, Petreucic V, Re D, Simbula G. Cytotoxicity evaluation of a new resin-based hybrid root canal sealer: an in vitro study. J Endod. 2014;40(1):124-8.

33. Cvek M. Prognosis of luxated non-vital maxillary incisors treated with calcium hydroxide and filled with gutta-percha. A retrospective clinical study. Dent Traumatol 1992; 8:4555.

34. Desai S and Chandler N. Calcium Hydroxide-Based Root Canal Sealers: A Review. J Endod. Apr 2009;35(4):475-80.

35. Dezan Junior, Eloi. Induçao experimental de anacorese no periapice de dentes após obturação dos canais: estudo em cães em região geográfica endêmica para leishmaniose. Tese (doutorado) - Faculdade de odontologia de Bauru. Universidade de São Paulo- Bauru, 2001

36. Dhivya S, Khandelwal N, Abraham SK, Premkumar K. Impact of Anthocyanidins on Mitoxantrone-Induced Cytotoxicity and Genotoxicity: An In Vitro and In Vivo Analysis. Integr Cancer Ther. 2016 May 4. In Press

37. Diomede F, Caputi S, Merciaro I et al. Pro-inflammatory cytokine release and cell growth inhibition in primary human oral cells after exposure to endodontic sealer. International Endodontic Journal 2014. 47:864-72.

38. Donnelly A, Sword J, Nishitani Y et al. Water sorption and solubility of methacrylate resin-based root canal sealers. Journal of Endodontics 2007. 33, 990-4.

39. Ersev H, Schmalz G, Bayirli G, Schweikl H. Cytotoxic and mutagenic potencies of various root canal filling materials in eukaryotic and prokaryotic cells in vitro. J Endod. 1999 May;25(5):359-63.

40. Evans $\mathrm{HJ}$, O'Riordan ML. Human peripheral blood lymphocytes for the analysis of chromosome aberrations in mutagen tests. Mutat Res. 1975 Jun;31(3):135-48.

41. Farré M, Gajda-Schrantz K, Kantiani L, Barceló D. Ecotoxicity and analysis of nanomaterials in the aquatic environment. Anal Bioanal Chem. 2009. Jan;393(1):8195.

42. Freshney RI. Culture of animal cells: a manual of basic technique. 5th ed. New York: Wiley-Liss; 2005. 
43. Fuks $A B$, Eidelman $E$, Pauker $N$. Root fillings with Endoflas in primary teeth: a retrospective study. J Clin Pediatr Dent. 2002 Fall;27(1):41-5.

44. Fuks $A B$. Pulp therapy for the primary and young permanent dentitions. Dent Clin North Am. 2000 Jul;44(3):571-96.

45. Gandolfi MG, Prati C. MTA and F-doped MTA cements used as sealers with warm guttapercha. Long-term study of sealing ability. International Endodontic Journal 2010. 43: 889-901.

46. Garlet GP, Cardoso CR, Silva TA, Ferreira BR, Avila-Campos MJ, Cunha FQ, et al. Cytokine pattern determines the progression of experimental periodontal disease induced by Actinobacillus actinomycetemcomitans through the modulation of MMPs, RANKL, and their physiological inhibitors. Oral Microbiol Immunol. 2006;21:12-20.

47. Garrido AD, de Cara SP, Marques MM, Sponchiado EC Jr, Garcia Lda F, de Sousa-Neto MD. Cytotoxicity evaluation of a copaiba oil-based root canal sealer compared to three commonly used sealers in endodontics. Dent Res J (Isfahan). 2015 Mar-Apr;12(2):1216.

48. Gatewood RS. Endodontic materials. Dent Clin North Am. 2007 Jul;51(3):695-712.

49. Gerosa R, Menegazzi G, Borin M, Cavalleri G. Cytotoxicity evaluation of six root canal sealers. J Endod. 1995;21:446-448.

50. Geurtsen W, Leyhausen G. Biological aspects of root canal filling materialshistocompatibility, cytotoxicity, and mutagenicity.Clinical Oral Investigations 1997. 1, 5-11.

51. Geurtsen W. Biocompatibility of root canal filling materials. Aust Endod J. 2001 Apr;27(1):12-21.

52. Goldstein BD. Hematological and toxicological evaluation of formaldehyde as a potential cause of human leukemia. Hum Exp Toxicol. 2011 Jul;30(7):725-35.

53. Gomes BP, Pedroso JA, Jacinto RC, Vianna ME, Ferraz CC, Zaia AA, de Souza-Filho FJ. In vitro evaluation of the antimicrobial activity of five root canal sealers. Braz Dent J. 2004;15(1):30-5. Epub 2004 Aug 16.

54. Guimarães $A C$, Antunes LM, Ribeiro HF, dos Santos AK, Cardoso PC, de Lima PL, Seabra AD, Pontes TB, Pessoa C, de Moraes MO, Cavalcanti BC, Sombra CM, Bahia Mde O, Burbano RR. Cytogenetic biomonitoring of inhabitants of a large uranium mineralization area: the municipalities of Monte Alegre, Prainha, and Alenquer, in the State of Pará, Brazil. Cell Biol Toxicol. 2010 Oct;26(5):403-19.

55. Gulati N, Chandra S, Aggarwal PK, Jaiswal JN, Singh M. Cytotoxicity of eugenol in sealer containing zinc-oxide. Endod Dent Traumatol. 1991 Aug;7(4):181-5.

56. Hargreaves KM, Cohen S. Caminhos da Polpa. Tradução Alcir Costa Frenandes Filho et al. - Rio de Janeiro. Elsevier, 2011. Cap.10. 
57. Hauman $\mathrm{CH}$, Love RM. Biocompatibility of dental materials used in contemporary endodontic therapy: a review. Part 2. Root-canal-filling materials. International Endodontic Journal 2003. 36, 147-60.

58. Hawkins JJ, Torabinejad M, Li Y, Retamozo B. Effect of three calcium hydroxide formulations on fracture resistance of dentin over time. Dent Traumatol. 2015 Oct; $31(5): 380-4$.

59. Heil J, Reifferscheid G, Waldmann P, Leyhausen G, Geurtsen W. Genotoxicity of dental materials. Mutation Research 1996. 368 :181-194.

60. Ho WY, Yeap SK, Ho CL, Rahim RA, Alitheen NB. Development of multicelular tumor spheroid (MCTS) culture from breast cancer cell and a high throughput screening method using the MTT assay. PLoS One. 2012;7(9).

61. Ho YC, Huang FM, Chang YC. Cytotoxicity of formaldehyde on human osteoblastic cells is related to intracellular glutathione levels. J Biomed Mater Res B Appl Biomater. 2007 Nov;83(2):340-4.

62. Huang FM, Chou LS, Chou MY, Chang YC. Protective effect of NAC on formaldehydecontaining- ZOE- based root- canal -sealers- induced cyclooxygenase-2 expression and cytotoxicity in human osteoblastic cells. J Biomed Mater Res B Appl Biomater. 2005 Aug; 74(2):768-73.

63. Huang FM, Tai KW, Chou MY, Chang YC. Cytotoxicity of resin-, zinc oxide-eugenol-, and calcium hydroxide-based root canal sealers on human periodontal ligament cells and permanent V79 cells. Int Endod J. 2002 Feb;35(2):153-8.

64. Huang TH, Lee $\mathrm{H}$, Kao CT. Evaluation of the genotoxicity of zinc oxide eugenol-based, calcium hydroxide-based, and epoxy resin-based root canal sealers by comet assay. J Endod. 2001 Dec;27(12):744-8.

65. Huang TH, Ding SJ, Hsu TZ, Lee ZD, Kao CT. Root canal sealers induce cytotoxicity and necrosis. Journal of Materials Science: Materials in Medicine, 2004. 15, 767-7.

66. Hume WR. An analysis of the release and the diffusion through dentin of eugenol from zinc oxide-eugenol mixtures. J Dent Res. 1984 Jun; 63(6):881-4.

67. International Agency of Research On Cancer. Cancer Incidence in Five Continents, Lyon: IARC Scientific Publications. 2006.

68. International Standard Organization (ISO) 10993-12:2004. Biological evaluation of medical devices - Part 12: Sample preparation and reference materials.

69. International Standard Organization (ISO) 10993-5:2009. Biological compatibility of medical devices - Part 5: Test for cytotoxicity: in vitro methods.

70. International Standard Organization (ISO) 7405:2008. Dentistry -- Evaluation of biocompatibility of medical devices used in dentistry.

71. Jafarnia B, Jiang J, He J, Wang YH, Safavi KE, Zhu Q. Evaluation of cytotoxicity of MTA employing various additives. Oral Surg Oral Med Oral Pathol Oral Radiol Endod. 2009 May;107(5):739-44. 
72. Jorge $\mathrm{JH}$, Giampaolo ET, Pavarina AC. Cytotoxicity of the dental materials. A literature review. Rev Odontol UNESP, 2004. 33(2):65-58.

73. Kawahara $\mathrm{H}$, Yamagami $\mathrm{A}$, Nakamura $\mathrm{M}$ Jr. Biological testing of dental materials by means of tissue culture. Int Dent J. 1968 Jun;18(2):443-67.

74. Keiser K, Johnson CC, Tipton DA. Cytotoxicity of mineral trioxide aggregate using human periodontal ligament fibroblasts. J Endod. 2000 May;26(5):288-91.

75. Koch $M J$, Wünstel $E$, Stein G. Formaldehyde release from ground root canal sealer in vitro. J Endod. 2001 Jun;27(6):396-7.

76. Kogan P, He J, Glickman GN, Watanabe I. The effects of various additives on setting properties of MTA. J Endod. 2006 Jun;32(6):569-72.

77. Konjhodzic-Prcic A, Jakupovic S, Hasic-Brankovic L, Vukovic A. Evaluation of Biocompatibility of Root Canal Sealers on L929 Fibroblasts with Multiscan EX Spectrophotometer. Acta Inform Med. 2015 Jun;23(3):135-7.

78. Kubota K, Golden BE, Penugonda B. Root canal filling materials for primary teeth: a review of the literature. ASDC J Dent Child. 1992 May-Jun;59(3):225-7.

79. Kulan P, Karabiyik O, Kose GT, Kargul B. Biocompatibility of Accelerated Mineral Trioxide Aggregate on Stem Cells Derived from Human Dental Pulp. J Endod. 2016 Feb;42(2):276-9.

80. Lee KW, Williams MC, Camps JJ, Pashley DH. Adhesion of endodontic sealers to dentin and gutta-percha. J Endod. 2002 Oct;28(10):684-8.

81. Leirskar J, Helgeland K. Mechanism of toxicity of dental materials. Int Endod J. 1981 Jan;14(1):42-7.

82. Leonardo MR, Bezerra da Silva LA, Filho MT, Santana da Silva R. Release of formaldehyde by 4 endodontic sealers. Oral Surg Oral Med Oral Pathol Oral Radiol Endod. 1999 Aug;88(2):221-5.

83. Leonardo MR, Hernandez ME, Silva LA, Tanomaru-Filho M. Effect of a calcium hydroxide-based root canal dressing on periapical repair in dogs: a histological study. Oral Surg Oral Med Oral Pathol Oral Radiol Endod. 2006 Nov;102(5):680-5.

84. Liang Y, Wang J, Yu S. [Mechanisms of bone repairment in periapical diseases: studies on adjusting bone metabolism with calcium hydroxide in vitro]. Zhonghua Kou Qiang Yi Xue Za Zhi. 2000 Mar;35(2):112-4.

85. Lindqvist $L$, Otteskog P. Eugenol: liberation from dental materials and effect on human diploid fibroblast cells. Scand J Dent Res. 1980 Dec;88(6):552-6.

86. Liu $P$, Guan R, Ye X.Toxicity of nano- and micro-sized silver particles in human hepatocyte cell line LO2. J Phys, 2011, 304:1-9.

87. Mandal P, Zhao J, Sah SK, Huang Y, Liu J. In vitro cytotoxicity of guttaflow 2 on human gingival fibroblasts. J Endod. 2014 Aug;40(8):1156-9. 
88. Marcantonio Junior E, Lia RCC, Marcantonio E, Benatti Neto C, Gabrielle MFR. Implantes subcutâneos de tubos de dentina preenchidos com materiais à base de hidróxido de cálcio, estudo histológico em ratos. Rev Odont UNESP 1984; 13: 39-49.

89. Martins VJ, Lins RX, Berlinck TC, Fidel RA. Cytotoxicity of root canal sealers on endothelial cell cultures. Braz Dent J. 2013;24(1):15-20.

90. Mendonça EF, Estrela C. Reparo após o tratamento endodôntico. In:Estrela, C, Figueiredo, JAP. Endodontia: Princípios Biológicos e mecânicos, São Paulo: Editora Artes Médicas, 2001; p.295-314.

91. Mestieri LB, Gomes-Cornélio AL, Rodrigues EM, Salles LP, Bosso-Martelo R, GuerreiroTanomaru JM, Tanomaru-Filho M. Biocompatibility and bioactivity of calcium silicatebased endodontic sealers in human dental pulp cells. J Appl Oral Sci. 2015 Oct;23(5):467-71.

92. Miletić I, Anić I, Karlović Z, Marsan T, Pezelj-Ribarić S, Osmak M. Cytotoxic effect of four root filling materials. Endod Dent Traumatol. 2000 Dec;16(6):287-90.

93. Montenegro MR, Facchio D. inflamações: conceitos gerais e inflamação aguda. In:Montenegro MR, Franco M. Patologia: Processos gerais. 4 ed. Sao Paulo: Atheneu, 2004. Cap.6, p.109-128.

94. Mortazavi M, Mesbahi M. Comparison of zinc oxide and eugenol, and Vitapex for root canal treatment of necrotic primary teeth. Int J Paediatr Dent. 2004 Nov;14(6):417-24.

95. Mosmann T. Rapid colorimetric assay for cellular growth and survival: application to proliferation and cytotoxicity assays. Journal of Immunologic Methods 1983. 65:5563.

96. Nawal RR, Parande $M$, Sehgal R, Naik A, Rao NR. A comparative evaluation of antimicrobial efficacy and flow properties for Epiphany, Guttaflow and AH-Plus sealer. Int Endod J. $2011 \mathrm{Apr} ; 44(4): 307-13$.

97. Nelson Filho P, Silva LA, Leonardo MR, Utrilla LS, Figueiredo F. Connectivetissue responses to calcium hydroxide-based root canal medicaments. Int Endod J.1999 Aug;32(4):303-11.

98. Orstavik D. Materials used for root canal obturation: technical, biological and clinical testing. Endod pics. 2005 12:30-41.

99. Osorio RM, Hefti A, Vertucci FJ, Shawley AL. Cytotoxicity of endodontic materials. J Endod. 1998 Feb;24(2):91-6

100. Ozorio JEV. Avaliação da quantidade de formaldeído liberado por alguns cimentos endodônticos, 2012 - 157p. Tese (Doutorado)- Faculdade de Odontologia de Ribeirão Preto, Universidade de São Paulo, Ribeirão Preto, 2012.

101. Parirokh $M$, Torabinejad $M$. Mineral trioxide aggregate: a comprehensive literature review--Part I: chemical, physical, and antibacterial properties. J Endod. 2010 Jan;36(1):16-27. 
102. Perassi FT, Filho IB, Berbert FL, Carlos IZ, de Toledo Leonardo R. Secretion of tumor necrosis factor-alpha by mouse peritoneal macrophages in the presence of dental sealers, sealapex and endomethasone. J Endod. 2004 Jul;30(7):534-7.

103. Pereira FEL, Bogliolo L. Inflamações. In: Bogliolo et al. Patologia geral. Rio de janeiro: Guanabara Koogan, 2009. Capt.7, p. 189-205.

104. Anusavice K, Shen C, Rawls H. Phillips Materiais Dentários. Tradução Roberto Braga. $12^{a}$ edição - Rio de Janeiro. Elsevier, 2013. 8: 160-89.

105. Pires CW, Botton G, Cadoná FC, Machado AK, Azzolin VF, da Cruz IB, Sagrillo MR, Praetzel JR. Induction of cytotoxicity, oxidative stress and genotoxicity by root filling pastes used in primary teeth. Int Endod J. 2015 Jul 14.

106. Poggio C, Ceci M, Dagna A, Beltrami R, Colombo M, Chiesa M. In vitro cytotoxicity evaluation of different pulp capping materials: a comparative study. Arh Hig Rada Toksikol. 2015 Sep 1;66(3):181-8.

107. Pongsavee M. In vitro study of lymphocyte antiproliferation and cytogenetic effect by occupational formaldehyde exposure. Toxicol Ind Health. 2011 Sep;27(8):719-23.

108. Pramila R, Muthu MS, Deepa G, Farzan JM, Rodrigues SJ. Pulpectomies in primary mandibular molars: a comparison of outcomes using three root filling materials. Int Endod J. 2016 May;49(5):413-21.

109. Preston RJ, San Sebastian JR, McFee AF. The in vitro human lymphocyte assay for assessing the clastogenicity of chemical agents. Mutat Res. 1987 Oct;189(2):175-83.

110. Queiroz AM, Assed S, Consolaro A, Nelson-Filho P, Leonardo MR, Silva RA, Silva LA. Subcutaneous connective tissue response to primary root canal filling materials. Braz Dent J. 2011;22(3):203-11.

111. Queiroz AM, Nelson-Filho P, Silva LA, Assed S, Silva RA, Ito IY. Antibacterial activity of root canal filling materials for primary teeth: zinc oxide and eugenol cement, Calen paste thickened with zinc oxide, Sealapex and EndoREZ. Braz Dent J. 2009;20(4):2906.

112. Ratanasathien S, Wataha JC, Hanks CT, Dennison JB. Cytotoxic interactive effects of dentin bonding components on mouse fibroblasts. J Dent Res. 1995 Sep;74(9):1602-6.

113. Reichl FX, Rothmund L, Shehata M, Högg C. DNA double-strand breaks caused by new and contemporary endodontic sealers. Int Endod J. 2015.

114. Ricucci D, Rôças IN, Alves FR, Loghin S, Siqueira JF Jr. Apically Extruded Sealers: Fate and Influence on Treatment Outcome. J Endod. 2016 Feb;42(2):243-9.

115. Rifkin A. A simple, effective, safe technique for the root canal treatment of abscessed primary teeth. ASDC J Dent Child. 1980 Nov-Dec;47(6):435-41.

116. Rodríguez-Lozano FJ, García-Bernal D, Oñate-Sánchez RE, Ortolani-Seltenerich PS, Forner L, Moraleda JM. Evaluation of cytocompatibility of calcium silicate-based endodontic sealers and their effects on the biological responses of mesenchymal dental stem cells. Int Endod J. 2015. 
117. Ruparel NB, Ruparel SB, Chen PB, Ishikawa B, Diogenes A. Direct effect of endodontic sealers on trigeminal neuronal activity. J Endod. 2014;40(5):683-7.

118. Sarigol CG, Cogulu D, Oncag O, Deliloglu IG. Cytotoxic effects of primary tooth root canal filling materials on L929 cell line. J Dent Child (Chic). 2010 May-Aug;77(2):72-6.

119. Savioli, RN. Avaliação das propriedades físico-químicas de alguns tipos de cimentos endodônticos à base de oxido de zinco-eugenol. Tese de doutorado. Usp- São Paulo 1998, 62p.

120. Scarparo RK, Grecca FS, Fachin EV. Analysis of tissue reactions to methacrylate resinbased, epoxy resin-based, and zinc oxide-eugenol endodontic sealers. J Endod 2009. 35:229-232.

121. Scelza MZ, Coil J, Alves GG. Effect of time of extraction on the biocompatibility of endodontic sealers with primary human fibroblasts. Braz Oral Res. 2012 SepOct;26(5):424-30.

122. Schafer E, Zandbiglari T. Solubility of root-canal sealers in water and artificial saliva. International Endodontic Journal 2003. 36,660-9.

123. Schmalz G. Use of cell cultures for toxicity testing of dental materials--advantages and limitations. J Dent. 1994; 22 Suppl 2:S6-11.

124. Schwarze T, Fiedler I, Leyhausen G, Geurtsen W. The cellular compatibility of five endodontic sealers during the setting period. J Endod. 2002; 28:784-786.

125. Schwarze T, Leyhausen G, Geurtsen W. Long-term cytocompatibility of various endodontic sealers using a new root canal model. J Endod. 2002 Nov;28(11):749-53.

126. Segato RA, Pucinelli CM, Ferreira DC, Daldegan Ade R, Silva RS, Nelson-Filho P, Silva LA. Physicochemical Properties of Root Canal Filling Materials for Primary Teeth. Braz Dent J. 2016 Apr;27(2):196-201.

127. Seltzer S. Pain in Endodontics. J Endod. 2004;30(7):501-3.

128. Seymour RA, Walton JG. Pain control after third molar surgery. Int J Oral Surg. $1984 ; 13(6): 457-85$.

129. Silva EJ, Neves AA, De-Deus G, Accorsi-Mendonça T, Moraes AP, Valentim RM, Moreira EJ. Cytotoxicity and gelatinolytic activity of a new silicon-based endodontic sealer. J Appl Biomater Funct Mater. 2015 Dec 18;13(4):376-80.

130. Silva GO, Cavalcanti BN, Oliveira TR, Bin CV, Camargo SE, Camargo CH. Cytotoxicity and genotoxicity of natural resin-based experimental endodontic sealers. Clin Oral Investig. 2016 May;20(4):815-9.

131. Silva RA, Assed S, Nelson-Filho P, Silva LA, Consolaro A. Subcutaneous tissue response of isogenic mice to calcium hydroxide based pastes with chlorhexidine. Braz Dent J. 2009;20(2):99-106. 
132. Siqueira Jr JF. Inflamação aguda: resposta vascular e celular. In: Siqueira Jr JF et al. Bases Moleculares da Inflamação. Rio de Janeiro: Guanabara Koogan, 2003. Cap. 6, p.73-82.

133. Siqueira Jr JF. Inflamação aguda: resposta vascular e celular. In: Siqueira Jr JF et al. Bases Moleculares da Inflamação. Rio de Janeiro: Guanabara Koogan, 2003. Cap. 7, p.83-103.

134. Souza LC, Yadlapati M, Dorn SO, Silva R, Letra A. Analysis of radiopacity, pH and cytotoxicity of a new bioceramic material. J Appl Oral Sci. 2015 Jul-Aug;23(4):383-9

135. Spagnuolo G, D'Anto V, Valletta $R$ et al.. Effect of 2-hydroxyethyl methacrylate on human pulp cell survival pathways ERK and AKT. Journal of Endodontics 2008. $34,684-8$.

136. Spangberg L, Pascon EA. The importance of material preparation for the expression of cytotoxicity during in vitro evaluation of biomaterials. J Endod. 1988 May;14(5):24750.

137. Spångberg LS, Barbosa SV, Lavigne GD. AH 26 releases formaldehyde. J Endod.1993 Dec;19(12):596-8.

138. Stoddart M. Mammalian Cell Viability. 1 ed. Humana Press, 2011. P.740

139. Størmer KJI, Attramadal A. Hvor funksjonsdyktige blir rotfylte unge permanente incisiver? Nordisk forening for pedodonti. Bergen, Norway: Årsmøte; 1988.

140. Tai KW, Huang FM, Huang MS, Chang YC. Assessment of the genotoxicity of resin and zinc-oxide eugenol-based root canal sealers using an in vitro mammalian test system. J Biomed Mater Res. 2002 Jan;59(1):73-7.

141. Takahashi K, Sawasaki Y, Hata J, Mukai K, Goto T. Spontaneous transformationand immortalization of human endothelial cells. In Vitro Cell Dev Biol. 1990Mar;26(3 Pt 1):265-74.

142. Tang Y, Zhu YQ, Wang HN, Han JL, He Y, Wang Y. [Comparison of three kinds of root canal disinfection medications in treatment of chronic apical periodontitis with fistula]. Shanghai Kou Qiang Yi Xue. 2010 Jun;19(3):236-9.

143. Tanomaru Filho M, Leonardo MR, Silva LA, Utrilla LS. Effect of different root canal sealers on periapical repair of teeth with chronic periradicular periodontitis. International Endodontic Journal 1998. 31, 85-9.

144. Tepel J, Darwisch el Sawaf M, Hoppe W. Reaction of inflamed periapical tissue to intracanal medicaments and root canal sealers. Endodontics and Dental Traumatology 1994. 10, 233-8.

145. Tice RR, Agurell E, Anderson D, Burlinson B, Hartmann A, Kobayashi H, Miyamae Y, Rojas E, Ryu JC, Sasaki YF. Single cell gel/comet assay: guidelines for in vitro and in vivo genetic toxicology testing. Environ Mol Mutagen. 2000;35(3):206-21.

146. Torabinejad M, Hong CU, McDonald F, Pitt Ford TR. Physical and chemical properties of a new root-end filling material. J Endod. 1995 Jul;21(7):349-53. 
147. Torabinejad M, Hong CU, Pitt Ford TR, Kettering JD. Antibacterial effects of some root end filling materials. J Endod. 1995 Aug; 21(8):403-6.

148. Tran QH, Nguyen VQ, Le AT. Silver nanoparticles: synthesis, properties, toxicology, applications and perspectives. Adv Nat Sci Nanosci Nanotechnol 2013;4:1-20.

149. Trowbridge HO. Immunological aspects of chronic inflammation and repair. J Endod. 1990 Feb;16(2):54-61.

150. Vajrabhaya L, Sithisarn P. Multilayer and monolayer cell cultures in a cytotoxicity assay of root canal sealers. Int Endod J. 1997 Mar;30(2):141-4.

151. Van Landuyt KL, Geebelen B, Shehata M, Furche SL, Durner J, Van Meerbeek B, Hickel R, Reichl FX. No evidence for DNA double-strand breaks caused by endodontic sealers. J Endod. 2012 May;38(5):636-41.

152. Vidal KAL. Estudo da citotoxicidade de tres cimentos obturaddore de canais endodônticos á base de óxido de xinco e eugebol em cultura de celular L929. Duque de Caxias, 2007. 97p. Dissertação (mestrado) - Universidade do Grande Rio ' ' 'Prof. José de Souza Herdy' ' - Duque de Caxias, Rio de Janeiro.

153. Wainstein M, Morgental RD, Waltrick SB, Oliveira SD, Vier-Pelisser FV, Figueiredo JA, Steier L, Tavares CO, Scarparo RK. In vitro antibacterial activity of a silicone-based endodontic sealer and two conventional sealers. Braz Oral Res. 2016;30(1).

154. Wataha JC. Principles of biocompatibility for dental practitioners. J Prosthet Dent. 2001 Aug;86(2):203-9.

155. Willershausen I, Callaway A, Briseño B, Willershausen B. In vitro analysis of the cytotoxicity and the antimicrobial effect of four endodontic sealers. Head Face Med. 2011 Aug 10;7:15.

156. Willershausen I, Wolf $T$, Kasaj A, Weyer V, Willershausen B, Marroquin BB. Influence of a bioceramic root end material and mineral trioxide aggregates on fibroblasts and osteoblasts. Archives of Oral Biology 2013. 58: 1232-7.

157. Wu MK, Dummer PM, Wesselink PR. Consequences of and strategies to deal with residual post-treatment root canal infection. Int Endod J. 2006 May;39(5):343-56.

158. Wyatt MD, Pittman DL. Methylating agents and DNA repair responses: Methylated bases and sources of strand breaks. Chem Res Toxicol. 2006 Dec;19(12):1580-94.

159. Xia X, Man Z, Jin H, Du R, Sun W, Wang X. Vitapex can promote the expression of BMP-2 during the bone regeneration of periapical lesions in rats. J Indian Soc Pedod Prev Dent. 2013 Oct-Dec;31(4):249-53.

160. Yilmaz Z, Dogan AL, Ozdemir O, Serper A. Evaluation of the cytotoxicity of different root canal sealers on L929 cell line by MTT assay. Dent Mater J. 2012;31(6):1028-32.

161. Yoshimine $Y$, Yamamoto M, Ogasawara T, Koishi Y, Tanabe K, Hashiguchi I, et al. In vitro evaluation of the cytocompatibility of a glass-lonomer cement sealer. J Endod. 2003;29:453-5. 
162. Yoshino $P$, Nishiyama CK, Modena KC, Santos CF, Sipert CR. In vitro cytotoxicity of white MTA, MTA Fillapex ${ }^{\circledR}$ and Portland cement on human periodontal ligament fibroblasts. Brazilian Dental Journal 2013. 24:111-6.

163. Zhang $H$, Pappen FG, Haapasalo $M$. Dentin enhances the antibacterial effect of mineral trioxide aggregate and bioaggregate. J Endod. 2009 Feb;35(2):221-4.

164. Zmener O, Banegas G, Pameijer $\mathrm{CH}$. Bone tissue response to a methacrylate-based endodontic sealer: a histological and histometric study. J Endod. 2005; 31:457-459. 
Versão Resumida em Inglês 



\section{VERSÃo RESUMIDA EM INGLÊS}

During the filling phase of root canals, there may be direct contact of the filling material with the periapical tissues, for an (indefinite) unknown period, which may delay, hinder or prevent the occurrence of the repair process, so for the success of endodontic treatment, selecting a suitable root canal shutter material is as essential as the operative technique. This contact can occur through leakage as puff' or even without extravasation, because derivatives components of these materials may come into direct contact with tissue through numerous connections, for example, the dentinal tubules, accessory canals, lateral canals and apical foramen, causing irritation and possible post-operative discomfort. Another way in which root canals sealers can be in contact with the periapical tissues is through the process of endodontic treatment in primary teeth due to root resorption process or endodontic treatment in immature teeth (open apex). For these reasons, the biocompatibility of the root canal filling material is extremely important. Thus, the objective of this study is to evaluate the cytotoxicity by MTT assay of six endodontic materials used in primary and permanent teeth (AH Plus ${ }^{\mathrm{TM}}$, GuttaFlow 2, Endomethasone N, Vitapex $\AA$, Calen $\AA$ thickened and MTA ProRoot) newly spatulate in primary cultures of peripheral human blood lymphocytes for 24 hours. The results were statistically analyzed by one-way ANOVA and Tukey's test at 5\% significance level. It was observed that the Endomethasone $\mathrm{N}$ was the most cytotoxic material for the lymphocytes, the AH Plus, and Calen $\AA$ thickened were cytotoxic from 25 $\mathrm{mg} / \mathrm{mL}$, while the MTA ProRoot, GuttaFlow 2 and Vitapex $($ were less cytotoxic for human lymphocytes, allowing to conclude that the Vitapex ${ }^{\circledR}$ (used in deciduous teeth) and GuttaFlow 2 and MTA ProRoot (used in permanent teeth) were less cytotoxic sealers on human lymphocytes.

Keywords: Cell viability, endodontics, MTT formazan, cytotoxicity, root canal sealer. 